\title{
Identifying potential areas for an expanding wolf population in Sweden
}

\author{
Therese Eriksson ${ }^{\mathrm{a}}$, Fredrik Dalerum ${ }^{\mathrm{a}, \mathrm{b}, \mathrm{c}^{*}}$ \\ ${ }^{a}$ Department of Zoology, Stockholm University, 10691 Stockholm, Sweden \\ ${ }^{\mathrm{b}}$ Research Unit of Biodiversity (UMIB, UO-CSIC-PA), Oviedo University - Campus Mieres, \\ 33600 Mieres, Spain
}

${ }^{\mathrm{c}}$ Mammal Research Institute (MRI), Department of Zoology and Entomology, University of Pretoria, Private Bag X20, Hatfield, 0028 South Africa

*Correspondence: dalerumjohan@uniovi.es

\begin{abstract}
Large carnivores have historically been decreasing worldwide, often as a result of humancarnivore conflicts. However, large carnivores are recovering throughout Europe, and European management scenarios can provide important insights into broad issues related to human-large carnivore existence. After becoming almost extinct in Sweden during the mid$19^{\text {th }}$ century the Swedish grey wolf (Canis lupus) population has now recovered. Current national wolf management aims to promote distribution shifts from the current areas in central Sweden, potentially also into a previously exempt reindeer husbandry area. Prior wolf re-introductions have highlighted the necessity of pro-active management for colonization success. Identification of likely range expansion areas could therefore be paramount for a successful Swedish wolf management. We characterized the demographic and spatial progression of Swedish wolves during 2001-2015 and used a maxent approach to species distribution models to identify potential range expansion areas. The Swedish wolf population had expanded from 10 to almost 60 reproductions or territorial pairs, and increased in both range size and density. Our distribution models suggested that Swedish wolf management may face trade-offs between costs of hosting wolves in densely populated areas in southern Sweden with cattle and sheep and the costs of allowing wolves to expand into reindeer husbandry areas with associated cultural and economic consequences. Spatially explicit data on the economic, social and cultural factors associated with wolf conflict and acceptance may be paramount for developing optimal management strategies in the face of such a trade-off.
\end{abstract}

Key words: Species distribution modeling, MaxEnt, range expansion, reindeer husbandry, carnivore management, wildlife conflict

Biological Conservation (2018) 220: 170-181 


\section{Highlights}

- The Swedish wolf population has shown a strong demographic expansion 2001-2015.

- A management policy has restricted the geographic distribution of Swedish wolves.

- Suitable range expansion areas were primarily found in northern or southern Sweden.

- Swedish wolf management will face trade-offs associated with future distribution.

- Policy can impact carnivore distributions more than environmental characteristics.

\section{Graphical abstract}
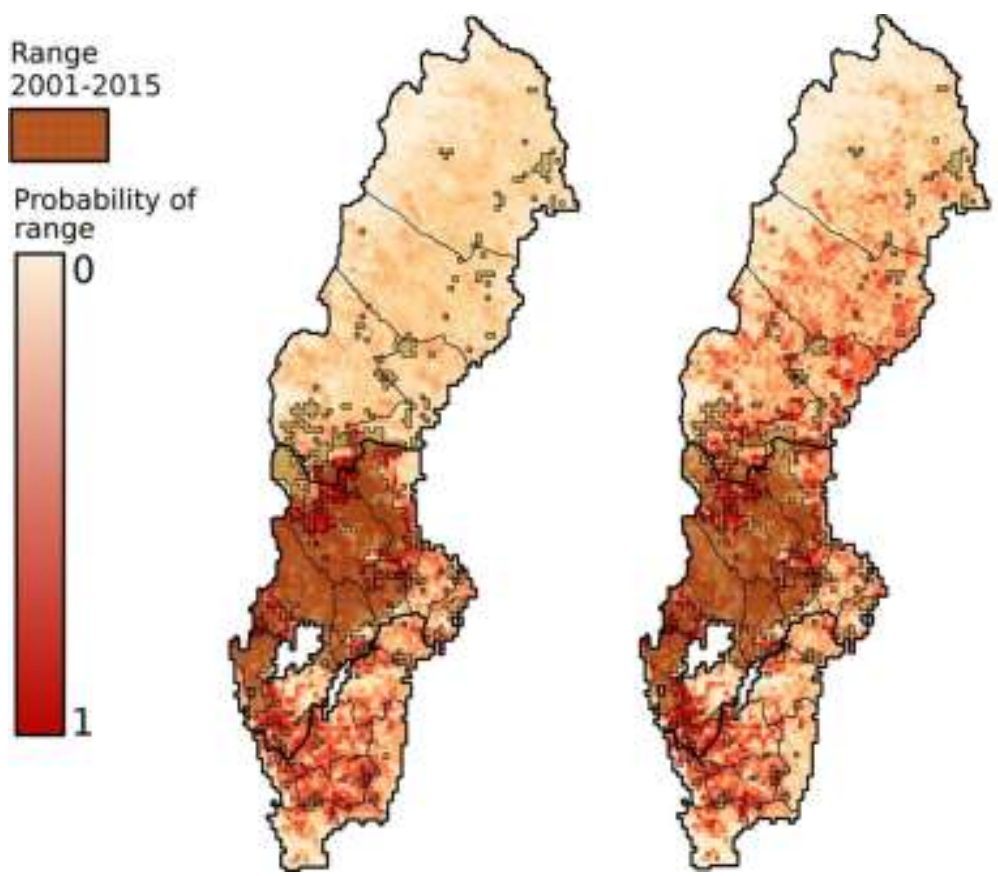

Wolf range suitability estimated from models including (left) and excluding (right) a reindeer husbandry area as a predictor identified areas in southern or northern Sweden as likely range expansion areas. 


\section{Introduction}

The distributions of many large carnivore species have historically been decreasing worldwide, partly due to conflicts with humans involving over-hunting or competition for territory (Dalerum et al. 2009). Conflicts occur when the needs of either humans or carnivores lead to a negative impact on the other. Finding ways towards promoting coexistence between humans and conflict prone species such as large carnivores is particularly relevant within the current paradigm of conservation biology, which is focused on finding sustainable solutions towards human-environmental co-existence (Mace 2014). Carnivores can cause damage to crops, injure or kill domestic animals or even people (Penteriani et al. 2016). Illegal killing of carnivores as retaliation can have severe effects on their populations (Madden 2004, but see Dalerum and Swanepoel 2017). Human-carnivore conflict also has economic implications, which tends to increase as human populations and their needs for agriculture and housing grow (Treves and Karanth 2003). Conflict is particularly prone to arise if management authorities fail to address the needs of communities living in proximity to wildlife (Madden 2004). Carnivore conservation is therefore becoming an increasingly political issue, with a subsequent need for pro-active rather than re-active management strategies (Ripple and Beschta 2011).

Although Europe is one of the most populated and industrially developed regions on Earth, many large carnivore populations have been restored and persist outside protected areas (Chapron et al. 2014). Hence, conflict resolution is important for European large carnivore management (Boitani et al. 2015), and Europe can function as an important region for developing and evaluating strategies towards sustainable integration of large carnivore populations into human dominated landscapes. Sweden is a country in northern Europe with relatively low human population densities, and is one of the few countries that hosts all four of Europe's large carnivore species (grey wolf Canis lupus, brown bear Ursus arctos, Eurasian lynx Lynx lynx and wolverine Gulo gulo) (Boitani et al. 2015). Despite large tracts of largely unpopulated, commercial coniferous forest, Sweden's expanding large carnivore populations have been causing an often intense and politically charged conflict, fuelled by public debate (Eriksson 2016). This is particularly prominent for the Swedish grey wolf population, which has attracted public attention and polarized emotional arguments far beyond what can be regarded as proportional to the potential problems it has caused (Eriksson et al. 2015).

Large carnivores in Sweden, including wolves, are owned and managed by the government, with the overall management responsibility resting on the Environmental Protection Agency (EPA). The Swedish wolf population was formally protected in 1966, at which point there were only about 10 individuals left in Scandinavia and no reproductive population in Sweden (Naturvårdsverket 2016). After protection, the first reproduction occurred in 1978, although the wolf population did not start to grow until approximately 15 years later (Wabakken et al. 2001). Since then the wolf population has continued to grow and the Swedish part of the Scandinavian population, which is shared between Sweden and Norway, is estimated to over 300 individuals (Wabakken et al. 2016). Human-wolf conflict in Sweden is primarily associated with semi pastoralist Sámi reindeer herders, politically powerful hunting organizations and to lesser extent rural livestock farmers (Nyrén 2012). The conflict between wolves and the Sámi reindeer husbandry has been particularly intense and politically charged. The Sámis form Swedens only indigenous cultural group. Much of the Sámis' current cultural identity is associated with reindeer husbandry practises (Daerga et al. 2008), which are made very difficult in the presence of wolves. This has lead previous Swedish policies for wolf management to exclude the reindeer husbandry area, which has a legally defined boundary (Swedish Reindeer Husbandry Act 1971), from areas were Swedish wolves are allowed to establish (Swedish Government, 2009). Moreover, a significant portion 
of the conflict is also associated with people who have no more direct contact with wolves than that they reside in wolf territories. This dimension of the conflict appears to primarily be based on fear (Frank et al. 2015), and the concept that resident wolf populations diminish the values of rural life styles (Karlsson and Sjöström 2007).

To minimize human-wolf conflict and simultaneously maintain a viable wolf population, the EPA has suggested a shift in wolf distribution across the country (Naturvårdsverket 2016). The shift would consist of decreasing wolf density in areas where density is currently high and facilitating the establishment of new territories where densities are currently low, including in the reindeer husbandry area as long as it does not have negative impacts on reindeer husbandry practises. Such a distribution shift, coupled with the often intense conflicts that arise in areas of recent colonization makes it imperative to predict suitable expansion areas (Mladenoff et al. 1999). Predictions of possible wolf distribution in Sweden have been made previously (e.g. Karlsson et al. 2007, Milleret 2016), and the range expansion of Swedish wolves has been linked to both intra- and interspecific population processes (Ordiz et al. 2015). However, previous approaches have focused on the scale of wolf home ranges within the current distribution range, which may be an inappropriate scale for current management practises (e.g., Balme et al. 2014). Consequently, none of the previous approaches have explicitly identified potential range expansion areas at suitable management scales.

In this study, we characterized the demographic and spatial progression of the Swedish wolf population during a phase of rapid expansion, from 2001 to 2015, and used a maximum entropy approach to environmental niche modelling to provide a nationwide perspective on potentially suitable areas for the geographic distribution of wolves in Sweden. Maximum entropy models have become an increasingly popular group of species distribution models because of their utility for presence-only data, their predictive accuracy even with limited sample sizes, and user friendliness (Baldwin 2009, Bassi et al. 2015, Merow et al. 2013, Phillips et al. 2006). Using a presence-only modeling technique can be favorable when dealing with wide-ranging species like wolves where reliable absence data might be difficult to obtain (Bassi et al. 2015). We used the freely available software MaxEnt (Phillips et al. 2006, Phillips et al. 2017) for our modeling exercises. Briefly, MaxEnt characterizes locations with species occurrences using the environmental variables, and then classifies all locations based on their similarities to these characteristics (Elith et al. 2011).

We have specifically; (i) evaluated demographic and spatial change of Swedish wolves over time, (ii) identified areas which are suitable for forming part of the geographic range of Swedish wolves, (iii) identified potential range expansion areas as suitable but previously unutilized areas, (iv) evaluated the impact of the previous exclusion of the reindeer husbandry area on wolf range suitability and range expansion areas, and (v) evaluated what environmental variables are associated with range expansion areas.

\section{Materials and methods}

\subsection{Study region}

Sweden takes up the majority of the Scandinavian Peninsula, and is stretching from $55^{\circ} 20 \mathrm{~N}$ to $69^{\circ} 03 \mathrm{~N}$. The country covers a land area of $438600 \mathrm{~km}^{2}$, excluding the four largest lakes. Sweden is characterized by vast forested areas, which make up nearly 70 percent of the country's surface. Most of this area is commercial forest. Approximately $3 \%$ of the land consists of built up areas and $8 \%$ of agriculture (Statistics Sweden 2013). Human population in Sweden is approximately 9 million people, with a density of 24.2 people $/ \mathrm{km}^{2}$ (Statistics Sweden, http://www.scb.se). Population density varies a lot with most of the densely populated areas being concentrated to the southern part of the country and along the Baltic 
seas coast. Sweden has varied climatic and environmental conditions, noticeable foremost on a north-south gradient. The climate is cold continental (Peel et al., 2007), with mean summer temperature ranging form 12 to $18^{\circ} \mathrm{C}$ and mean winter temperature from -18 to $2^{\circ} \mathrm{C}$.

Northern boreal forests are dominated by scots pine (Pinus sylvestris) and Norwegian spruce (Picea abies) trees, although birch (Betula sp.) is also common. The southernmost part of the country harbors some deciduous forest including beech (Fagus sylvatica), aspen (Populus tremula), birch (Betula sp.) and common oak (Quercus robur).

About half of Sweden's land area, from the central parts and northwards, is defined as a reindeer grazing zone, and can be utilized for semi domesticated reindeer husbandry by the native Sámi people (Swedish Reindeer Husbandry Act 1971). Within this area native Sámi people use the land for reindeer husbandry. Approximately 250000 reindeer are kept under free ranging conditions, primarily in the mountainous regions during the summer and in the boreal forest during the winter. Reindeer husbandry activities are often in conflict with large carnivores, and the conflicts with wolves are particularly intense. Most other livestock in Sweden are fenced. However, livestock related damages do occur on sheep, with approximately 400 sheep being killed annually by wolves, as well as on cattle and dogs, although damages on these latter species are less intense (approximately 10 and 35 killed annually, respectively; http://www.slu.se/viltskadecenter). Most of these livestock damages occur in the central management region (Selby 2016).

Although the EPA has the ultimate responsibility of carrying out national policies regarding large carnivore management, practical management is largely carried out on a regional level. Each of Sweden's 21 counties are responsible for defining and carrying out their own regional carnivore management plans, under the condition that they do not conflict with the overall national goals defined by the EPA. Responsibilities resting with each county include defining regional minimum population sizes and geographic distributions, as well as defining and implementing regional strategies regarding sustainable hunting (Naturvårdsverket 2016). To facilitate the necessary coordination under this regionalized management, the counties are clustered into three carnivore management regions.

Our study focused on 20 of Sweden's 21 counties. We omitted the county of Gotland, since this Baltic island lacks wolf presence and was excluded from the latest national management plan for wolves (Naturvårdsverket 2016). The island of Öland has also lacked wolf presence in recent history and was similarly excluded from the study, although we have included the mainland part of Kalmar County which the island belongs to.

\subsection{Wolf occurrence data}

We used wolf occurrence data that are collected annually by management authorities as part of routine population monitoring (Liberg et al. 2012). The data were supplied by the EPA and consisted of an extract from an official data base jointly managed by Swedish and Norwegian authorities. Data primarily included spatial locations of observations, tracks or genetic samples collected during field inventories that are carried out by county board staff during the winter season (October $1^{\text {st }}$ to March $31^{\text {st }}$ ), but we also included the locations of dead wolves reported to the Swedish Veterinary Institute. Data from radio-collared wolves and camera traps are also used to map the wolf population, but were not made available for our analyses. In total, our data set consisted of 16228 individual locations (Supplementary material, Appendix 1).

\subsection{Quantification of demographic and spatial change}

The main goal of the Swedish national wolf monitoring is to document the number of family groups and scent-marking pairs on a national as well as on a county level (Naturvårdsverket 2016). Hereafter we will refer to both of these demographic entities as "demographic units". 
The Swedish national wolf monitoring includes both intensive field monitoring as well as individual identification of wolves using genetic techniques. Although it provides a robust estimate of the number of demographic units, it is not designed to accurately estimate group size, and hence the number of individual wolves (Naturvårdsverket 2016). To describe wolf demography over time, we used the official annual summaries of the number of demographic units. Lone stationary or wandering wolves were not included since they do not contribute demographically to the population. Inventory data were divided by county and carnivore management region. Demographic units that were found in two or more counties during the same inventory period were shared equally between counties, i.e. if a demographic unit was observed in two counties, each county was given 0.5 of a demographic unit or 0.33 if a demographic unit was observed in three counties. No demographic units were found in the southern management region.

We used the raw observations from the wolf inventories to calculate wolf distribution range. The range was calculated using a raster with a grid-cell size of $8.5 \times 8.5 \mathrm{~km}(72.25$ $\mathrm{km}^{2}$ ). This size corresponds to the required home range size for a pack of four wolves where prey densities are at an average high level, in order for the pack to meet nutritional requirements (Mech and Boitani 2003). Although this home range size is smaller than the ones recorded in Sweden (ranging from 256 to $1676 \mathrm{~km}^{2}$, Mattison et al. 2013), it reflects an ecologically defined spatial entity that we regard appropriate for national level analyses (e.g., Swanepoel et al. 2013). The same cell size was used for the species distribution model, described below. A cell was regarded as part of the distribution range if it contained a wolf occurrence during a specific year and it or any of its adjacent cells had an occurrence also the preceding year. We used this restriction to filter out locations that were either misidentifications or observations of dispersing animals that were observed outside the normal species range.

We regressed number of wolf demographic units, geographic range sizes, wolf density and wolf density within the wolf range against time for Sweden, each management region and each county separately. In addition, we evaluated differences in these temporal trends at two separate scales, between management regions and between counties within management regions. We made these comparisons by evaluating interaction terms between time and geographic area (i.e. management region or county) in three separate mancova models, one using data for the northern and central management region, and two more for the northern and central management region, respectively. All of these analyses were restricted to regions and counties that had demographic units located within them for at least five years during the study period. To evaluate if the distribution range of Swedish wolves had expanded in a spatially nested pattern, we calculated the nested temperature suggested by RodríguezGironés and Santamaría (2006) as an index of spatial nestedness. In our application, nestedness describes the extent to which cells included in the range of a given year also forms part of the distribution the following years (Ulrich et al. 2009). The nested temperature varies from 0 , which indicates complete nestedness, to 100, which indicates no nestedness. We evaluated if the observed nested temperature deviated from random expectations by comparing it to the values from 999 null models which were constrained to retain the original marginal sums.

\subsection{Species distribution modeling in MaxEnt}

\subsubsection{Environmental variables used for species distribution modeling}

We used 23 environmental variables as the basis for our species distribution models (Supplementary Material, Appendix 1). These variables were associated with climate, vegetation, geomorphology and human impact (Swanepoel et al. 2013). Although we appreciate that social and economic variables would be valuable complements to these 
Table 1 Environmental variables used for the spatial modeling. All variables except the reindeer husbandry area are continuous.

\begin{tabular}{|c|c|c|}
\hline Variable & Description & Source \\
\hline Cattle density & Average number of cattle (2010-2014) & The Swedish board of Agriculture \\
\hline Pig density & Average number of pigs (2010-2014) & The Swedish board of Agriculture \\
\hline Sheep density & Average number of sheep (2010-2014) & The Swedish board of Agriculture \\
\hline Forest & Percentage of area taken up by forest (2014) & Swedish Land Survey \\
\hline Marshland & Percentage of area taken up by marshland (2014) & Swedish Land Survey \\
\hline Open land & Percentage of area taken up by fields per pixel (2014) & Swedish Land Survey \\
\hline Inland water & Percentage of area taken up by open water per pixel (2014) & Swedish Land Survey \\
\hline Land cover heterogeneity & Shannon index of land cover evenness & Swedish Land Survey \\
\hline Protected areas & $\begin{array}{l}\text { Percentage of area taken up by national parks and nature } \\
\text { reserves (2014) }\end{array}$ & Swedish Land Survey \\
\hline Elevation & $\begin{array}{l}\text { Mean elevation re-sampled from } 50 \mathrm{~m} \text { resolution Digital } \\
\text { Elevation Model }\end{array}$ & Swedish Land Survey \\
\hline Terrain ruggedness & $\begin{array}{l}\text { Terrain ruggedness calculated from } 50 \mathrm{~m} \text { resolution Digital } \\
\text { Elevation Model }\end{array}$ & Swedish Land Survey \\
\hline NDVI & $\begin{array}{l}\text { Normalized Difference Vegetation Index, calculated from } \\
\text { MODIS MOD13Q1. } 250 \text { m resolution ( } 16 \text { days average, } \\
\text { July 2010). }\end{array}$ & $\begin{array}{l}\text { NASA EOSDIS Land Processes DAAC, USGS Earth } \\
\text { Resources Observation and Science (EROS) Center, Sioux } \\
\text { Falls, South Dakota (https://lpdaac.usgs.gov), accessed } \\
\text { 2016-02-15 }\end{array}$ \\
\hline Precipitation & Mean annual precipitation (1961-1990) & Swedish Meteorological and Hydrological Institute \\
\hline Road density $<7 \mathrm{~m}$ & Density of private and public roads $<7$ m wide (2014) & Swedish Land Survey \\
\hline Road density $>7 \mathrm{~m}$ & Density of roads and highways $>7 \mathrm{~m}$ wide (2014) & Swedish Land Survey \\
\hline Human density & Average human population density (2014) & Statistics Sweden \\
\hline Reindeer husbandry area & Reindeer husbandry area, categorical variable (2010) & Reindeer Husbandry Land use database, IRENMARK \\
\hline
\end{tabular}


environmental predictors, the lack of spatially explicit information across suitable scales prevented us from utilizing such information in our models. We only retained variables that correlated less than $70 \%$ for final analyses. We removed 6 variables due to high spatial covariance with other variables: percentage cover of alpine areas (correlated with elevation and maximum temperature), percentage cover of urban areas (correlated with population density), maximum, mean and minimum temperature (correlated with each other, vegetation period, the alpine range and reindeer husbandry area) and vegetation period (correlated with reindeer husbandry area). We chose which variables to retain based on their ecological relevance (Jędrzejewski et al. 2004, Mattisson et al. 2013). After the removal of correlated variables, we retained 16 continuous and 1 categorical variables as predictors of wolf range suitability (Table 1). Although none of these predictors directly quantified prey densities, habitat suitability for both moose (Alces alces) and roe deer (Capreolus capreolus), the main prey for Swedish wolves (Wikenros et al. 2009), are directly related to many of the included variables, such as the availability of forest and habitat heterogeneity (e.g., Tufto et al. 1996, Dettki et al. 2003). All environmental variables were projected to the equal area projection

SWEREF99TM and converted to raster format with a grid-cell size of $8.5 \times 8.5 \mathrm{~km}$. The two major lakes Vänern and Vättern were removed since it is unlikely that these large water bodies provide refuge for wolves. Coastal islands and islets smaller than the size of one cell were also removed before any analyses were made.

\subsubsection{Basic MaxEnt modeling characteristics}

We used the software MaxEnt 3.4.1 to create distribution models describing suitable areas for wolf ranges in Sweden (Phillips et al. 2017). Modeling was carried out by calling MaxEnt from $\mathrm{R}$ version 3.3.3 for Linux (http://www.r-proj.org) using the packages dismo version 1.012 (Hijmans et al. 2017) and ENMeval version 0.2.0 (Muscarella et al. 2014). We used the center coordinate of each grid cell that at some point had been classified as wolf distribution range during the period 2001-2015 as species presence localities. Hence, the models evaluate the suitability of range distribution rather than of occurrence. This yielded a total of 1266 presence localities to be used in the modeling exercise. We used 500 iterations, a convergence threshold of $10^{-5}$ and values from all 6022 cells in the nationwide grid as background samples.

\subsubsection{Model selection and evaluation}

MaxEnt models fall within a category of analyses that is more concerned with accuracy of predictions than with explanatory power (Warren and Seifert 2011). Hence, models fitted using MaxEnt are generally more complex than models fitted using likelihood based algorithms. This property means that it can be informative to include more predictors than what would be regarded as appropriate for likelihood based models. However, model simplification may still be beneficial since over-fitting often has adverse effects on model performance (Phillips and Dudík 2008), and fine tuning of model parameters generally improves predictive abilities (Muscarella et al. 2014). MaxEnt associates the locations of presences to environmental values of using 5 different feature types, which represent different types of parameterizations. In addition, MaxEnt has a built in mechanism to control for over-fitting using a regularization parameter that can be used to penalize variables which add little to the model. Hence, model complexity in MaxEnt can be controlled for in three principal ways; i) by varying the included environmental layers, ii) by varying the number and types of included feature types, and iii) by varying the degree of regularization, i.e. the penalization of parameters with low contribution to model performance. However, currently there is no consensus regarding the best method for detecting optimal model settings (Muscarella et al. 2014). 
We ran two sets of models, one including the full set of uncorrelated environmental variables (model I), and one excluding the reindeer husbandry area (model II) to evaluate the potential effect of the management strategy to exclude the reindeer husbandry area on potential wolf distribution and suitable range expansion areas (Swanepoel et al. 2013). For each model, we fixed the environmental layers to the 17 or 16 (excluding the reindeer husbandry area) uncorrelated variables described above, but created candidate models containing all types of feature combinations, each run over a set of regularization multipliers ranging from 0 to 10. We used Akaike's Information Criterion (AICc; Akaike 1974) to identify the best combination of regularization and feature types to construct one model from each set. Although likelihood based methods such as AIC values may be at odds with the MaxEnt model philosophy, AICc select bad models less often than AUC-based methods and has been suggested to select models with better average performance (Warren and Seifert 2011). Following Burnham and Anderson (2002), we treated models within 2 AICc units below the model with the lowest value as having approximately equal empirical support. We ran the model simplification separately for each of the two sets of environmental variables, i.e. with and without the reindeer husbandry area.

We evaluated model performance in three separate ways. First, we used the area under the receiver operating characteristic (ROC) curve (AUC) based on a model using the full set of observations as training data. The AUC gives a measure of predictive accuracy of the model, with AUC values $\leq 0.5$ indicating a model of no predictive ability whereas a value of 1.0 indicates maximum ability to distinguish between training and background locations. AUC-values $>0.7$ can be considered fair and values $>0.8$ indicate a good model (Araújo et al. 2005). Second, we used three metrics based on cross validations to evaluate model performance. We based these metrics on a portioning of our data set into two separate bins of training and testing data using a checkerboard method, which uses a grid across the study extent to partition the locations with even spatial extents of training and testing data (Muscarella et al. 2014). $\mathrm{AUC}_{\text {test }}$ is a threshold-independent metric that describes the ability of testing locations to distinguish between presence and background locations (Hanley and McNeil 1982). The $\mathrm{AUC}_{\text {diff }}$ describes the difference in the ability of the training and testing data to distinguish between presence and background locations. Large differences are generally associated with over fitting (Warren and Seifert 2011). The 10\% training omission rate $\left(\mathrm{OR}_{10}\right)$ is a threshold dependent metric that quantifies the proportion of test localities with fitted values lower than that excluding the $10 \%$ of training localities with the lowest predicted suitability. Omission rates higher than $10 \%$ usually suggests an over fitted model (Fielding and Bell 1997).

Second, we evaluated the ability of the selected model with the full set of environmental variables to predict wolf range by dividing the data into 5-year bins (i.e. 2001-2005, 20062010, and 2011-2015), and training two models using only location data from each of the first two time bins. For each of these two models, we evaluated the proportion of the range expansion (i.e. the range in a bin period that was not used in the previous bin period) that occurred within the predicted range expansion areas. Range expansion areas were calculated by extracting the range area for the bin period from the binary classification of suitable range, see below.

\subsubsection{Projection of model output, binary classification of suitable range and identification of range expansion areas}

We have presented our models both as a binary classification of suitable range areas and as a cloglog projection of raw values, which can be interpreted as a probability of range occurrence (Phillips et al. 2017). To create our binary classification, we used a method that finds the values which maximizes both sensitivity and specificity, since this method has been 
shown to produce more robust and consistent results compared to other methods (Liu et al. 2016). Here, sensitivity is defined as the proportion of correctly predicted presences among all presence locations, and specificity is defined as the proportion of correctly predicted absences among all absence locations (Liu et al. 2013). We based this binary classification of the cloglog transformed output.

To calculate future range expansion areas, we extracted the total range distribution (pooled from 2001 to 2015) from the binary classification of the MaxEnt output and identified the remaining areas as potential range expansion areas, i.e. previously unoccupied suitable range areas. These were summarized for each geographic scale, i.e. nationwide, management regions and counties.

\subsubsection{Evaluating the impact of the reindeer husbandry area}

Since previous policies have dictated that no wolf presence should be allowed within the reindeer husbandry area, it presents a policy caused constraint on recent wolf distribution in Sweden (Naturvårdsverket 2016). In order to quantify the effectiveness of this policy constraint we specifically evaluated the impact of the reindeer husbandry area on wolf range suitability in two separate ways. First, we compared the proportion of potential range expansion areas in each region and county between the predictions based on the model with and without the reindeer husbandry as a predictor. Secondly, we subtracted the cloglog values from the model including the reindeer husbandry area from those of the model excluding it, and summarized the pixel values of this difference for each region and county.

\subsubsection{Evaluating variable contributions and associations between environmental variables and range expansion areas}

We evaluated the relative contribution of each environmental variable to the two MaxEnt models both using a heuristic method and using jackknife tests. In the heuristic method, the percent contribution of each predictor was calculated as the proportional contribution of each predictor to the model training gain for every iteration of the model fitting process (Phillips et al., 2006). The jackknife test showed the gain in AUC value of each environmental variable when used in isolation as well as the loss of gain when removed from the full set of variables (Phillips et al. 2006).

We evaluated if the potential range expansion areas differed in environmental characteristics from the utilized range areas using a logistic approach. First, we selected all cells that had been part of the identified range during the study period, as well as the cells that were identified as suitable range expansion zones, i.e. cells identified as suitable using the binary classification of our two MaxEnt models but that had not been part of the identified range. We then coded each cell as being utilized as range or not during our study period, and used this binary variable as a response in generalized linear models (GLM) with binomial error functions and logit links using the main effects of the environmental variables in each cell as predictors. We did separate analyses for the range areas predicted from each of our two MaxEnt models, i.e. the one with the full set of environmental variables and the one not including the reindeer husbandry area. To account for spatial autocorrelation, we added up to $6^{\text {th }}$ order polynomials of the spatial coordinates to the GLM predictors (Borcard et al. 2011). We selected this level of complexity for eliminating spatial autocorrelation by sequentially adding polynomial terms until the spatial autocorrelation in the model residuals, measured by Moran's I (Moran 1950), had been eliminated. We appreciate that the MaxEnt algorithms per definition will try to find a set of cells that has a minimal difference between these two classes of locations. However, because of the inherent complexity of the MaxEnt models, and because we here are only interested in a very specific subset of the background locations, we still regard this logistic approach as informative. 


\section{Results}

\subsection{Temporal change in demography, distribution range and density}

From 2000 to 2015, the Swedish wolf population expanded demographically from 10 to almost 60 demographic units (Fig. 1a). Most of the demographic units were observed in the central management region, which had a higher increase in the number of demographic units than the northern region $(F=345.13, \mathrm{df}=1,26, \mathrm{p}<0.001)$. There were similarly differences between counties in the increase in the number of demographic units, both within the northern $(F=4.20, \mathrm{df}=1,26, \mathrm{p}=0.051)$ and central management region $(F=30.61, \mathrm{df}=$ $6,91, \mathrm{p}<0.001)$. Despite these differences, there were significant positive trends in the number of demographic units in all counties of both the northern and southern management region except Västra Götaland in the central management region (Table 2). No demographic units were recorded in the southern management region (Supplementary Material, Table A1).

The demographic expansion was associated with an increased geographic range during 2001-2009, although this range expansion appears to have been haltered during 2010-2015 (Fig. 1b). In total, wolf range occupied approximately $91500 \mathrm{~km}^{2}(20.8 \%$ of Sweden's land area) during 2001 to 2015 , with a maximum annual range of $34800 \mathrm{~km}^{2}(7.9 \%$ of Sweden's land area). As with the increase in number of demographic units, most of the range expansion occurred in the central management region (Fig. 2), which also had a higher increase in range area than the northern region $(F=15.88, \mathrm{df}=1,26, \mathrm{p}<0.001)$. There were differences between counties in the increase in wolf range area in both the northern $(F=9.64$, df $=1,26$, $\mathrm{p}<0.001)$ and the central management region $(F=4.61, \mathrm{df}=6,91, \mathrm{p}<0.001)$, but there were significant positive trends in all counties that had hosted territories except for Västernorrland (Table 2). The nested temperature of wolf range expansion in Sweden did not differ significantly from random expectations $\left(\mathrm{T}_{\mathrm{obs}}=26.62, \mathrm{~T}_{\exp }=26.11, \mathrm{z}=1.25, \mathrm{p}=0.105\right)$, suggesting that the expansion had been accompanied by annual range shifts rather than an expansion from a central core area.

The demographic expansion lead to significant increases in wolf density (Fig. 1c), although the central management region had a higher increase in density than the northern management region $(F=379.27, \mathrm{df}=1,26, \mathrm{p}<0.001)$. There were also differences among counties in the central management region $(F=4.67, \mathrm{df}=6,91, \mathrm{p}<0.001)$, with significantly increased densities in all counties except Västra Götaland (Table 2). While there were similar significant increases in density within the wolf range (Fig. 1d), these increases did not differ between the northern and central management regions $(F=0.07, \mathrm{df}=1,26, \mathrm{p}=0.793)$ or between the counties in the northern management region $(F=0.12, \mathrm{df}=1,26, \mathrm{p}=0.737)$. There were, however, significant differences in the increases in density within the wolf range among counties in the central management region $(F=5.67, \mathrm{df}=6,91, \mathrm{p}<0.001)$, with only Värmland and Västmanland having experienced significant increases (Table 2).

A detailed summary of demographic change over time is available in Supplementary material, Table A1.

\subsection{MaxEnt model evaluation}

For model I, containing a full set of predictor variables, the optimal structure had a regularization multiplier of 2 and contained linear, quadratic, hinge and product features. For Model II, excluding the reindeer husbandry area, the optimal structure had a regularization multiplier of 1.5 and contained linear, quadratic, threshold and product features. The selected models had AICc values that were 7.20 (model I) and 6.02 (model II) units below the models with the second lowest values, AUC values of 0.799 and 0.781 , and they contained 63 parameters and 72 parameters, respectively (Supplementary material, Table A2). More 

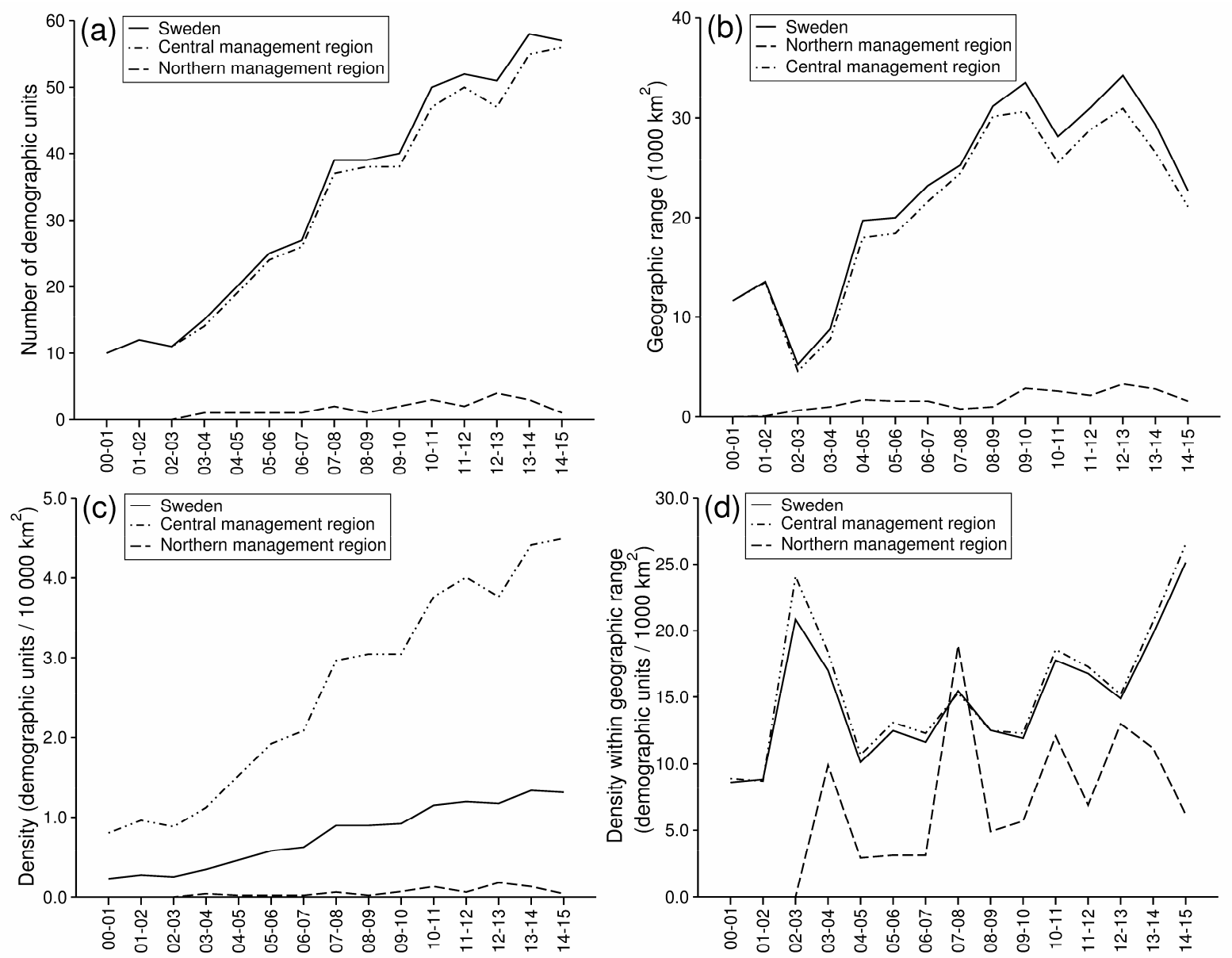

Fig. 1 The number of wolf demographic units (a, family groups or scent marking pairs), wolf range size (b), wolf density (c, number of demographic units per $10000 \mathrm{~km}^{2}$ ) and wolf density within the wolf range (d) in the northern and central management region as well as nationally in Sweden during $2000-2015$. The graphs are based on official data from the Swedish Environmental Protection Agency. No demographic units were recorded in the southern management region during the time period, although we identified small areas as belonging to the geographic range (maximum of $722.5 \mathrm{~km}^{2}$ per year, 12 of the 15 years had less than $220 \mathrm{~km}^{2}$ identified as range, Supplementary material, Table A1). 


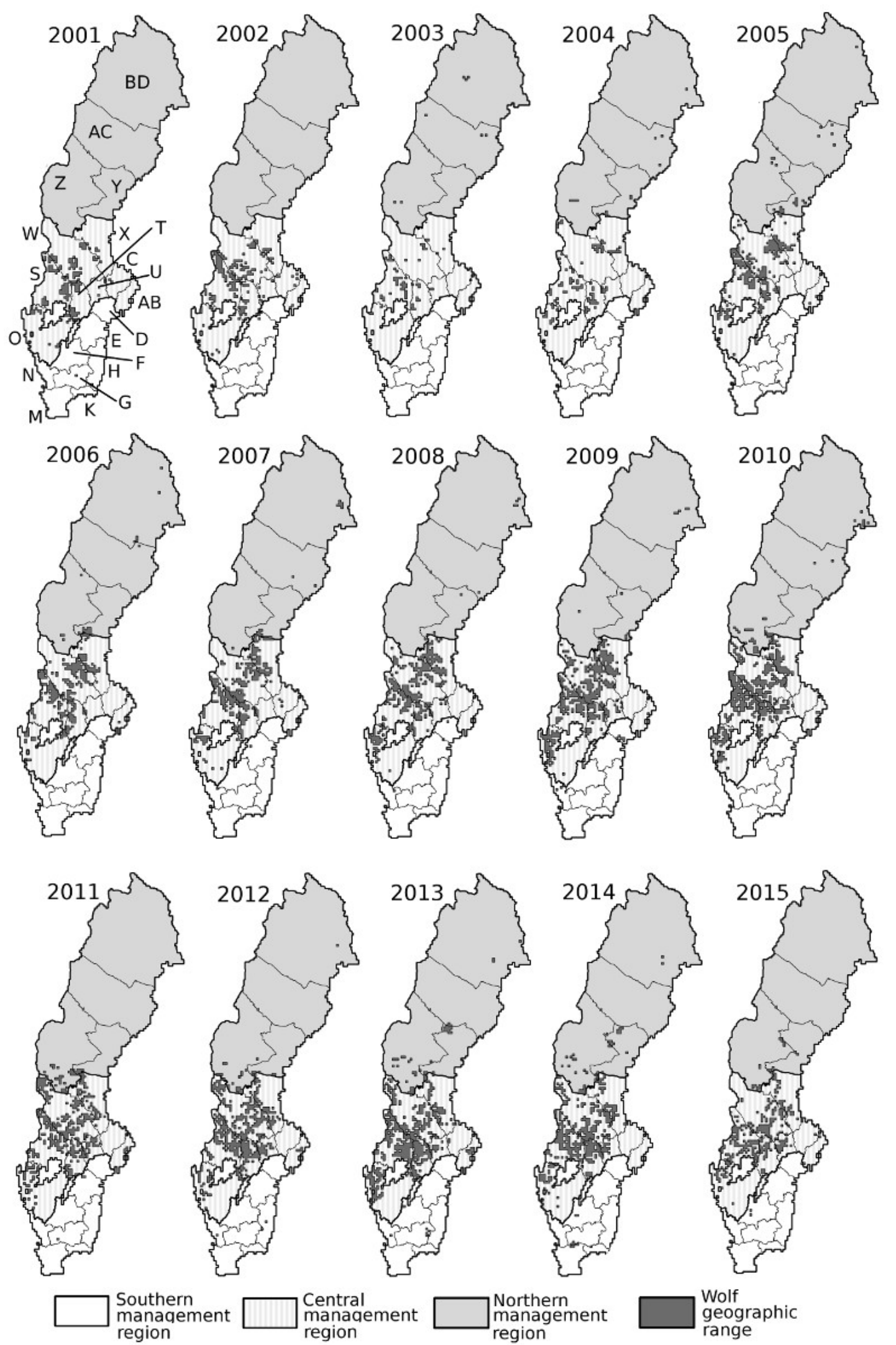

Fig. 2 Wolf geographic range in the northern, central and southern carnivore management region in Sweden from 2001 to 2015 . Wolf range was calculated as $8.5 \times 8.5 \mathrm{~km}$ cells where wolves had been observed a given year and if wolves had been observed in the same or any of its neighboring cells also the preceding year. 
Table 2 Beta values describing the temporal trends for the wolf territories, the geographic range of Swedish wolves, territory density and territory density within the geographic range for Sweden, the northern and central management regions as well as all counties that hosted wolf territories for at least five years during the period 2000-2015. No range areas were identified in the southern management region. Significant pvalues were set to $<0.05$.

\begin{tabular}{|c|c|c|c|c|c|c|c|c|c|c|c|c|}
\hline & \multicolumn{3}{|c|}{$\begin{array}{l}\text { Number of } \\
\text { demographic units }\end{array}$} & \multicolumn{3}{|c|}{ Geographic range } & \multicolumn{3}{|c|}{ Wolf density } & \multicolumn{3}{|c|}{$\begin{array}{l}\text { Wolf density within } \\
\text { geographic range }\end{array}$} \\
\hline & $\beta$ & $\mathrm{t}_{1}$ & $\mathrm{p}$ & $\beta$ & $\mathrm{t}_{1}$ & $\mathrm{p}$ & $\beta$ & $\mathrm{t}_{1}$ & $\mathrm{p}$ & $\beta$ & $\mathrm{t}_{1}$ & $\mathrm{p}$ \\
\hline$\underline{\text { Sweden }}$ & 3.88 & 20.46 & $<0.001$ & 1662.78 & 4.93 & $<0.001$ & 0.09 & 20.46 & $<0.001$ & 0.62 & 2.62 & 0.021 \\
\hline Northern & 0.20 & 4.31 & 0.001 & 179.33 & 4.58 & 0.001 & 0.01 & 3.83 & 0.002 & 0.71 & 2.52 & 0.026 \\
\hline Västernorrland (Y) & 0.05 & 2.77 & 0.016 & 36.38 & 1.75 & 0.104 & 0.00 & 1.17 & 0.262 & 0.90 & 2.94 & 0.012 \\
\hline Jämtland (Z) & 0.15 & 3.30 & 0.006 & 150.43 & 4.97 & $<0.001$ & 0.03 & 3.30 & 0.006 & 0.49 & 0.43 & 0.674 \\
\hline Central & 3.67 & 20.33 & $<0.001$ & 1483.45 & 4.57 & 0.001 & 0.29 & 20.33 & $<0.001$ & 0.60 & 2.13 & 0.052 \\
\hline Örebro (T) & 0.50 & 6.20 & $<0.001$ & 191.46 & 4.48 & 0.001 & 0.52 & 6.20 & $<0.001$ & 0.81 & 1.69 & 0.115 \\
\hline Västmanland (U) & 0.34 & 8.06 & $<0.001$ & 113.54 & 5.59 & $<0.001$ & 0.58 & 8.06 & $<0.001$ & 1.88 & 3.69 & 0.003 \\
\hline Dalarna (W) & 1.17 & 7.54 & $<0.001$ & 480.98 & 3.70 & 0.003 & 0.39 & 7.54 & $<0.001$ & 0.51 & 1.36 & 0.198 \\
\hline Gävleborg (X) & 0.25 & 3.30 & 0.006 & 194.04 & 2.40 & 0.032 & 0.13 & 3.30 & 0.006 & -0.76 & -1.46 & 0.169 \\
\hline Värmland (S) & 1.23 & 13.46 & $<0.001$ & 325.64 & 4.59 & 0.001 & 0.64 & 13.46 & $<0.001$ & 1.05 & 4.24 & 0.001 \\
\hline Västra Götaland (O) & 0.08 & 0.97 & 0.348 & 163.59 & 2.71 & 0.018 & 0.03 & 0.97 & 0.348 & -1.62 & -1.30 & 0.217 \\
\hline
\end{tabular}


complex models than these generally showed clear signs of over fitting, whereas less complex models lost predictive abilities (Supplementary material, Fig. A1).

The model built on range data from 2001 to 2005 predicted $82.2 \%$ of the range expansion areas during the subsequent 5 year period (i.e. 2006 to 2010), with the highest sensitivity in the central (91.3\% predicted range expansion) and southern management regions $(75.0 \%)$, although the model had much lower sensitivity in the northern management region $(11.0 \%)$. The model built on range data from 2006 to 2010 predicted $64.7 \%$ of the range expansion areas during 2011 to 2015 , again with the highest sensitivity in the central (76.7 \% predicted range) and southern management region $(80.5 \%)$ and much lower sensitivity in the northern management region (16.3\%).

\subsection{Predicted range distribution, potential expansion areas and effects of the reindeer husbandry area}

Most areas identified as suitable wolf range by the MaxEnt model including the full set of environmental predictors were concentrated to the central management region, with a sharp decline in suitability north of the border of the reindeer husbandry area (Fig. 3a). Excluding the reindeer husbandry area as a predictor variable gave a more dispersed distribution of suitable range areas, primarily increasing range suitability in northern Sweden (Fig. 3b). Most of the increase in range subsequently occurred in the northern management region, but also in the south-western parts of the central management region, while the central parts of the central management region were estimated to be of lower suitability when removing the reindeer husbandry area as a predictor (Fig. 3c).

Using the full model, most range expansion areas, i.e. areas identified as suitable but that had been not been previously utilized, could be found in the southern management region (Fig. 4a), although the central management region also hosted nearly half of the range expansion areas (Table 3). Using the model without the reindeer husbandry area, more range expansion areas were identified in the northern management region (Fig 4b), at the expense of both the central and southern management regions. Using this model, the range expansion areas were approximately equally distributed among the three management regions (north $39.2 \%$, central $28.2 \%$ and south $32.6 \%$ of range expansion areas) (Table 3 ).

\subsection{MaxEnt variable contributions and characteristics of range expansion zones}

In the full model, the reindeer husbandry area was the most influential variable, with a contribution of $56.1 \%$, followed by forest cover (14.9\%), precipitation $(9.7 \%)$, cattle density (9.5\%), NDVI (3.3\%), density of small roads $(3.1 \%)$ and elevation $(2.3 \%)$. In the model not including the reindeer husbandry area, density of small roads was the most influential variable with a contribution of $30.4 \%$, followed by precipitation $(29.3 \%)$, forest cover (17.1\%), NDVI (13.7\%), cattle density (6.1\%) and elevation (1.3\%). All remaining variables had contributions of less than $1 \%$ for each respective model (Supplementary material, Table A3). The relative importance of the different variables was supported by the jackknife tests, both for the full model (Supplementary material, Fig. A2a) and the model not including the reindeer husbandry area (Supplementary material, Fig. A2b).

Potential range expansion areas identified from both the full MaxEnt model and the model not including the reindeer husbandry area had significantly higher elevation than utilized range, but potential range expansion areas did not differ from utilized range for any of the other environmental variables (Table 4).

\section{Discussion}

Our study highlighted several aspects of both the demographic and spatial progression of Swedish wolves, as well as the prospective for further spatial expansion that are informative 


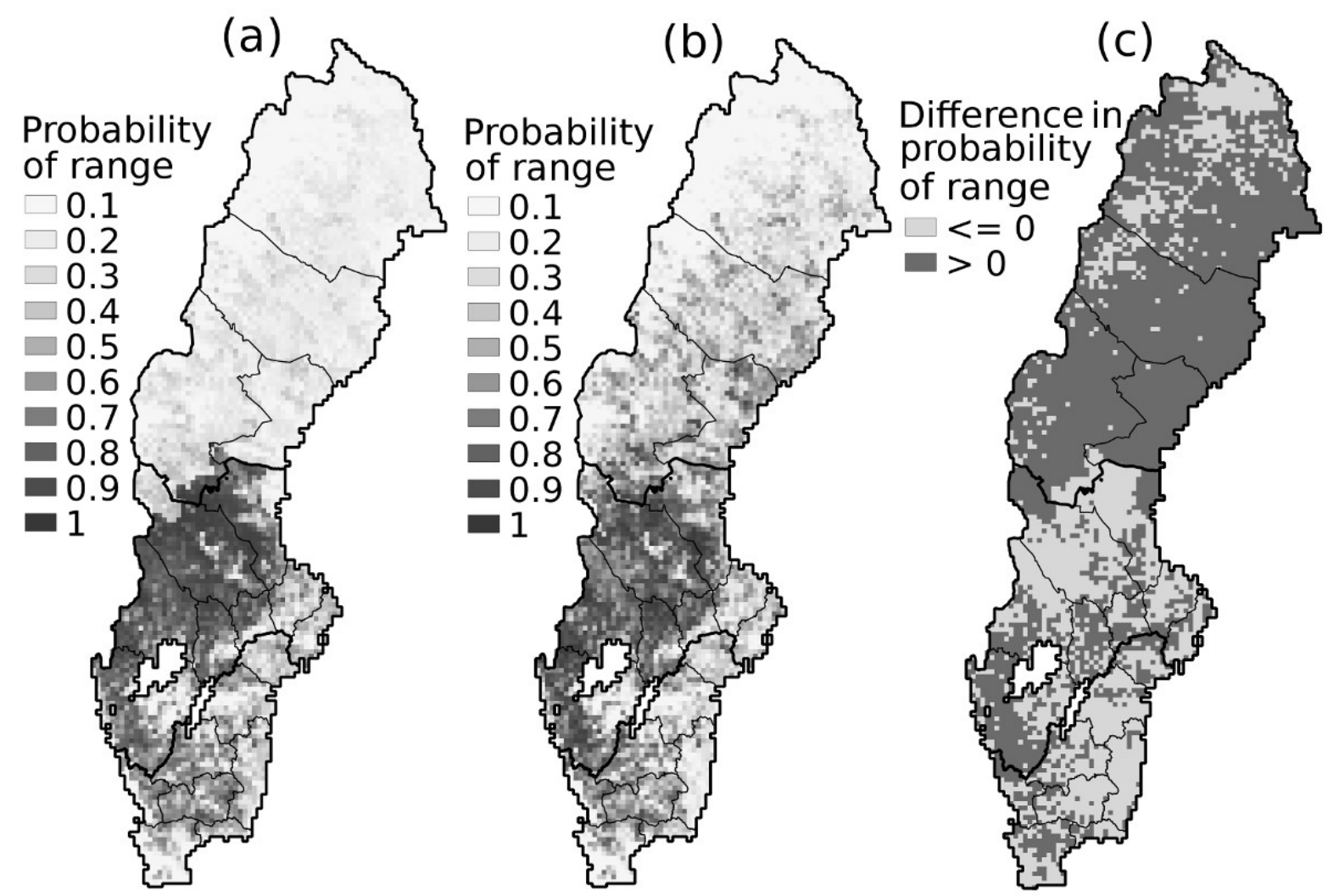

Fig. 3 Predicted range suitability, estimated as probability of range, according to a MaxEnt model using 17 environmental variables (a) and according to a MaxEnt model using the same variables except the reindeer husbandry area (b), as well as a binary classification of the difference in probability of range presence between the model excluding and including the reindeer husbandry area (c). In this classification, values above 0 indicate that the pixel had higher probability of range when the reindeer husbandry area was not considered. 

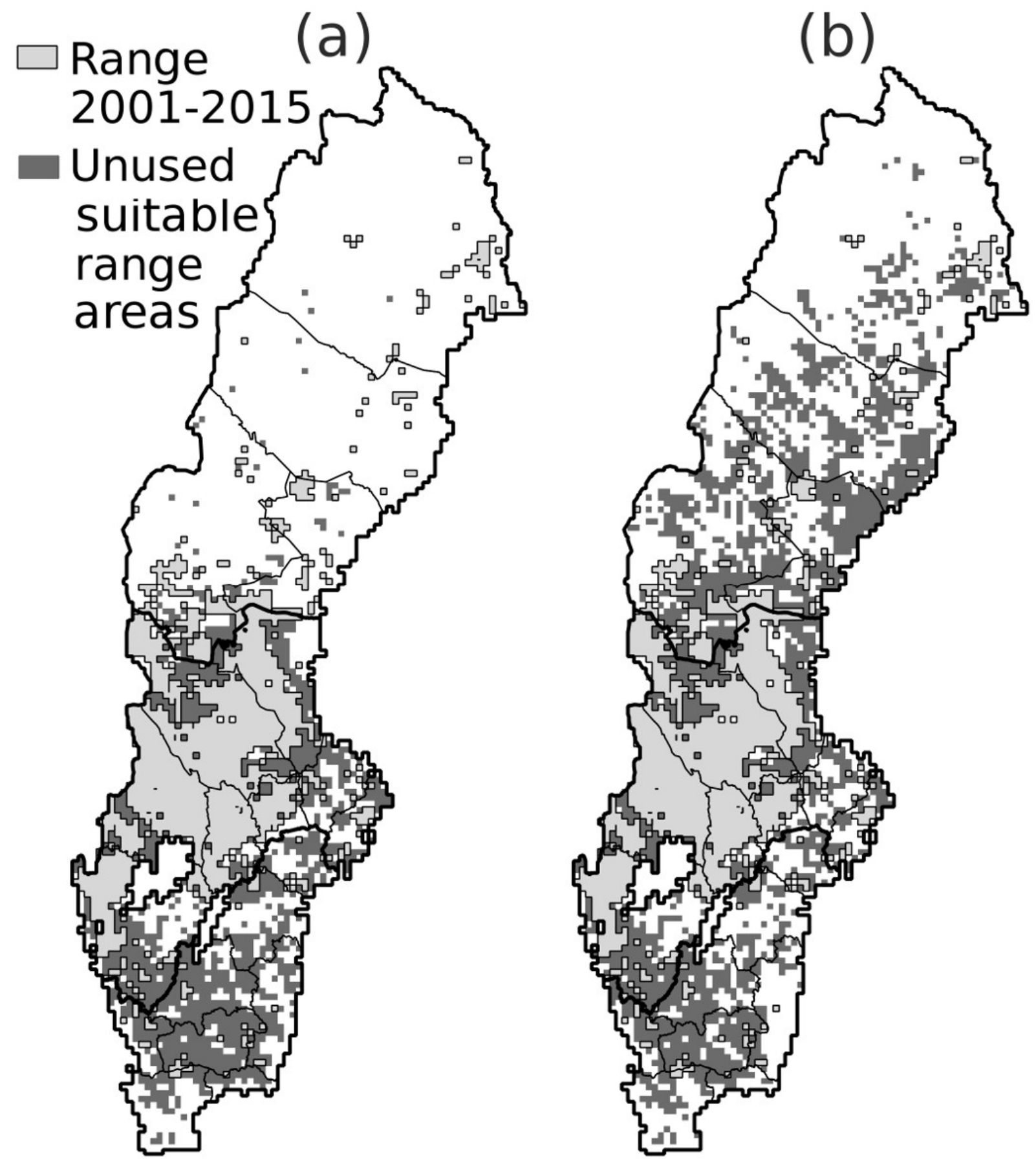

Fig. 4. The distribution range of Swedish wolves 2001-2015 as unused suitable wolf range areas based on a MaxEnt model using 17 environmental variables (a) and based on a MaxEnt model using the same variables except the reindeer husbandry area (b). 
Table 3 Area of occupied wolf range 2001 to 2015 in each management region and county, the proportion of range in each region and county, the areas and proportions of unused suitable range according to one MaxEnt model including the reindeer husbandry area (Model I) and one excluding it as a predictor (Model II), as well as the average difference in probability of distribution range between model I and II calculated across $8.5 \times 8.5 \mathrm{~km}$ pixels.

\begin{tabular}{|c|c|c|c|c|c|c|c|}
\hline & $\begin{array}{l}\text { Range } \\
2001-2015 \\
\left(10000 \mathrm{~km}^{2}\right)\end{array}$ & range & $\begin{array}{l}\text { Model I* } \\
\text { Area unused } \\
\left(10000 \mathrm{~km}^{2}\right)\end{array}$ & $\begin{array}{l}0 \text { of } \\
\text { nused }\end{array}$ & $\begin{array}{l}\text { Model II** } \\
\text { Area unused } \\
\left(10000 \mathrm{~km}^{2}\right)\end{array}$ & $\begin{array}{l}\% \text { of } \\
\text { unused }\end{array}$ & $\begin{array}{l}\text { Difference in range } \\
\text { probability } \\
(\text { mean }+\mathrm{sd})\end{array}$ \\
\hline Northern & 1.52 & 16.69 & 0.00 & 0 & 2.16 & 39.24 & $4 \quad 0.13 \pm 0.12$ \\
\hline Jämtlands län (Z) & 0.74 & 8.07 & 0.00 & 0 & 0.70 & 12.73 & $0.12 \pm 0.14$ \\
\hline Norrbottens län (BD) & 0.27 & 2.93 & 0.00 & 0 & 0.02 & 0.39 & $0.04 \pm 0.07$ \\
\hline Västerbottens län (AC) & 0.13 & 1.42 & 0.00 & 0 & 0.89 & 16.14 & $0.13 \pm 0.11$ \\
\hline Västernorrland län (Y) & 0.39 & 4.27 & 0.00 & 0 & 0.55 & 9.97 & $0.22 \pm 0.15$ \\
\hline Central & 7.24 & 79.27 & 2.82 & 47.85 & 1.55 & 28.22 & $-0.01 \pm 0.12$ \\
\hline Dalarnas län (W) & 2.26 & 24.76 & 0.35 & 6.01 & 0.33 & 5.91 & $-0.01 \pm 0.15$ \\
\hline Gävleborgs län (X) & 1.03 & 11.31 & 0.55 & 9.33 & 0.21 & 3.81 & $-0.04 \pm 0.19$ \\
\hline Örebro län (T) & 0.78 & 8.54 & 0.07 & 1.23 & 0.04 & 0.79 & $0.02 \pm 0.07$ \\
\hline Stockholms län (AB) & 0.11 & 1.19 & 0.26 & 4.42 & 0.02 & 0.39 & $-0.03 \pm 0.08$ \\
\hline Uppsala län (C) & 0.12 & 1.27 & 0.37 & 6.26 & 0.07 & 1.18 & $-0.04 \pm 0.08$ \\
\hline Värmlands län (S) & 1.63 & 17.88 & 0.26 & 4.42 & 0.16 & 2.89 & $-0.04 \pm 0.10$ \\
\hline Västmanlands län (U) & 0.37 & 4.03 & 0.05 & 0.86 & 0.01 & 0.13 & $0.01 \pm 0.07$ \\
\hline Västra Götalands län (O) & 0.94 & 10.28 & 0.90 & 15.34 & 0.72 & 13.12 & $0.03 \pm 0.08$ \\
\hline$\underline{\text { Southern }}$ & 0.37 & 4.03 & 3.66 & 62.09 & 1.79 & 32.55 & $-0.04 \pm 0.08$ \\
\hline Blekinge län (K) & 0.00 & 0.00 & 0.16 & 2.70 & 0.05 & 0.92 & $-0.03 \pm 0.08$ \\
\hline Hallands län (N) & 0.07 & 0.71 & 0.29 & 4.91 & 0.24 & 4.33 & $0.02 \pm 0.08$ \\
\hline Jönköpings län (F) & 0.05 & 0.55 & 0.83 & 14.11 & 0.53 & 9.71 & $-0.03 \pm 0.07$ \\
\hline Kalmar län $(\mathrm{H})$ & 0.03 & 0.32 & 0.45 & 7.61 & 0.08 & 1.44 & $-0.10 \pm 0.08$ \\
\hline Kronobergs län (G) & 0.08 & 0.87 & 0.78 & 13.25 & 0.48 & 8.79 & $-0.06 \pm 0.07$ \\
\hline Östergötlands län (E) & 0.06 & 0.63 & 0.56 & 9.45 & 0.16 & 2.89 & $-0.07 \pm 0.08$ \\
\hline Skåne län (M) & 0.03 & 0.32 & 0.33 & 5.52 & 0.22 & 4.07 & $0.01 \pm 0.06$ \\
\hline Södermanlands län (D) & 0.06 & 0.63 & 0.27 & 4.54 & 0.02 & 0.39 & $0.00 \pm 0.08$ \\
\hline
\end{tabular}

* Including the reindeer husbandry area as an environmental predictor

** Not including the reindeer husbandry area as an environmental predictor 
Table 4. Beta coefficients from generalized linear models contrasting the values of environmental variables between areas included in the wolf geographic distribution range 2001 to 2015 and areas identified as suitable range areas but that have not been utilized by wolves. Suitable range areas were identified from binary classifications of MaxEnt models based on the full set of environmental variables (Model I) and on all environmental variables except the reindeer husbandry area (Model II).

\begin{tabular}{|c|c|c|c|c|c|c|}
\hline \multirow[b]{2}{*}{ Variable } & \multicolumn{3}{|c|}{ Model I } & \multicolumn{3}{|c|}{ Model II } \\
\hline & $\beta$ & Z & $\mathrm{p}$ & $\beta$ & $\mathrm{Z}$ & $\mathrm{p}$ \\
\hline Cattle density & 0.14 & 0.82 & 0.415 & 0.17 & 0.76 & 0.447 \\
\hline Pig density & 0.27 & 1.59 & 0.111 & 0.27 & 1.22 & 0.224 \\
\hline Sheep density & 0.03 & 0.32 & 0.746 & -0.04 & -0.43 & 0.666 \\
\hline Forest & -0.64 & -1.25 & 0.210 & -0.77 & -1.12 & 0.261 \\
\hline Marshland & -0.25 & -1.20 & 0.229 & -0.30 & -1.11 & 0.269 \\
\hline Open land & -0.09 & -0.25 & 0.804 & -0.16 & -0.34 & 0.732 \\
\hline Inland water & 0.04 & 0.23 & 0.820 & 0.10 & 0.40 & 0.686 \\
\hline Land cover heterogeneity & 0.08 & 0.50 & 0.618 & -0.09 & -0.49 & 0.623 \\
\hline Protected areas & -0.02 & -0.08 & 0.937 & 0.01 & 0.05 & 0.960 \\
\hline Elevation & 0.67 & 1.98 & 0.047 & 0.62 & 1.92 & 0.055 \\
\hline Terrain ruggedness & 0.04 & 0.66 & 0.508 & 0.11 & 1.49 & 0.136 \\
\hline NDVI & -0.01 & -0.09 & 0.927 & -0.07 & -0.66 & 0.512 \\
\hline Precipitation & -0.19 & -1.39 & 0.163 & -0.03 & -0.16 & 0.875 \\
\hline Road density $<7 \mathrm{~m}$ & -0.07 & -0.64 & 0.521 & -0.01 & -0.08 & 0.937 \\
\hline Road density $>7 \mathrm{~m}$ & 0.01 & 0.05 & 0.958 & 0.09 & 0.74 & 0.459 \\
\hline Human density & 0.08 & 0.44 & 0.658 & 0.03 & 0.09 & 0.927 \\
\hline Reindeer husbandry area & 0.37 & 0.75 & 0.455 & & & \\
\hline
\end{tabular}


for large carnivore conservation and management elsewhere. First, the data showed that policy decisions, if implemented rigorously, can limit the distribution even of a wide ranging species like the wolf. This have had local consequences in terms of increased densities in the central parts of Sweden, which have caused the Swedish management authorities to adapt a policy of promoting the spatial expansion of the distribution range of Swedish wolves. In the light of this policy, our MaxEnt modeling suggested that Swedish wolf managers may face trade-offs between one distinct set of cultural and economic conflict in southern Sweden, linked primarily to high human population densities and livestock husbandry, and an ethnic, cultural and economic conflict associated with reindeer husbandry in the northern parts of the country. The relative costs stemming from these contrasting conflicts needs to be weighted against any potential benefits stemming from wolves being allowed to expand into the different areas of Sweden. Although a significant body of research has been produced related to solving biological trade-off scenarios in conservation (reviewed in Leader-Williams et al. 2010), we argue that the trade-offs associated with future Swedish wolf management largely is economic and social, and ultimately political. This is likely a general property associated to large carnivore management policies, and we argue that we have an important role as conservation biologists to provide ecological and biological information to assist in developing optimal strategies facing complex socio-economic and environmental decision scenarios (Dalerum 2014).

The Swedish wolf population more than quadrupled during the study period although it remained largely in the central management region. Much of the northern part of Sweden consists of boreal forest, which could be regarded as suitable wolf habitat (Mech and Boitani 2003). The concentration of Swedish wolves in the central management region therefore highlights the impact of the policy decision to exclude the reindeer husbandry area from potential wolf range, for both the distribution and densities of Swedish wolves. The subsequent increase in densities in central Sweden may have lead to an increased level of conflict (e.g., Eriksson et al. 2015). For instance, annually wolves only occupied fractions of the total area of the total range during the period 2001-2015, with the maximum annual range size being only approximately $38 \%$ of the total range. Coupled with our lack of detected spatial nestedness in the range expansion, this pattern could indicate small scale range shifts associated with local persecution (Liberg et al. 2011). Although a strategy of allowing wolves to spread outside of this central management region may alleviate some of the present conflict, it is likely to cause new conflicts in the colonization areas. However, increased knowledge and experience about how to prepare for and handle encounters with apex predators have led to greater acceptance towards these animals in certain parts of Europe, such as Austria and Italy (Esenrink and Vogel 2006), and pro-active approaches were fundamental in the success of the re-introduction of wolves to the greater Yellowstone ecosystem (Ripple and Beschta 2011). We therefore highlight that preparations in terms of public information campaigns in likely future colonization areas could be key to the success of the current Swedish wolf management strategy, which targets a broader range distribution with subsequent re-colonization of areas that has lacked wolves in recent history (Naturvårdsverket 2016).

By combing maximum entropy models with public wolf survey data we identified areas that are likely to be colonized if the Swedish wolf population is allowed to expand its range. Including the reindeer husbandry area in our models effectively excluded all of northern Sweden from being classed as suitable range areas. Subsequently, using this model most of the identified expansion areas were found in the central and southern parts of Sweden, with the highest proportion of expansion areas occurring in the southern management region. This management region has previously not hosted any wolf territories, and our results suggest that there may be possibilities for range establishment particularly in the central parts of 
southern Sweden, if there is social acceptance and subsequent lack of strong persecution (e.g., LLaneza et al. 2012). In contrast, when we used the MaxEnt model without the reindeer husbandry area we identified substantial parts of northern Sweden as suitable for potential range expansion. These areas were mostly distributed along the Baltic sea coast, in the southern parts of the county of Jämtland and along the major river valleys in the central parts of northern Sweden. Some of these areas are utilized as reindeer winter grazing grounds by the Sámi (Gränsdragningskommissionen 2006), and wolf colonization would likely have consequences for the reindeer herding community. However, allowing a population expansion into northern Sweden may allow an increased connectivity into other European populations, which potentially could alleviate some of the reported inbreeding problems of the Scandinavian wolves (e.g., Vilá et al. 2002; Flagstad et al. 2002; Kardos et al. 2018).

We highlight that the potential social and economic costs of a northern colonization must be weighted against the potential costs of reaching acceptable levels of social acceptance in the more densely populated areas of southern Sweden, which also has higher densities of potentially damage sensitive livestock such as sheep and cattle (e.g., Ahmadi et al. 2013). Such an evaluation should include an estimation of the relative increases in the costs of livestock compensation programs, but also more indirect costs associated with hosting carnivore populations in areas with different social, economic and environmental characteristics. These contrasting conflicts highlight the often difficult trade-offs that are involved with conflict prone wildlife species (reviewed in Woodroffe et al. 2005). Hence, the development of optimal strategies in the face of this trade-off is essential if Sweden is to meet its management goal of shifting the current wolf distribution (Naturvårdsverket 2016). The development of such strategies would greatly benefit from an evaluation of spatially explicit data on socioeconomic factors associated with conflict and local carnivore acceptance. Although several studies have evaluated real and perceived conflict associated with- and social acceptance of large carnivores in Sweden (e.g., Karlsson and Sjöström 2007, Liberg et al. 2011, Frank et al. 2015, Eriksson et al. 2015, Eriksson 2016), studies have not been spatially explicit. Hence, we call for further evaluations that would enable the development of spatial priorities based on economic, cultural and social information in a spatial framework across Sweden. Such data could for instance facilitate the creation of environmental niche models that use a combination of environmental, economic and social variables to evaluate range suitability across a given area such as a country, management region, or distribution range. Another approach to use spatially explicit conflict data would be to super-impose them on the current models, to identify the suitable range expansion areas that are least likely to be associated with different aspects of conflict.

The reindeer husbandry area had the overall largest contribution of any environmental variable in our MaxEnt models. This exemplifies that policy decisions can be more important than environmental conditions in determining the distribution range of wildlife species, even if they are completely free ranging (in contrasts to species confined to fenced reserved, e.g., the wild dog Lycaon pictus population in South Africa, Davies-Mostert et al. 2009). For both MaxEnt models, forest cover, precipitation, elevation and NDVI also contributed to the MaxEnt model solutions, as well as cattle density and density of small roads, two variables associated with human activity. Hence, a combination of ecological, climatic, geological and anthropogenic variables seems to have contributed to wolf range suitability. These results generally agree with the view of wolves as a habitat generalist (Mech and Boitani 2003, see also Jędrzejewski et al. 2004 and Smith et al. 2015). Similarly, although some studies have demonstrated negative influences of human populations and associated activities on wolf habitat use (Karlsson et al. 2007, Smith et al. 2015), others have not found such associations (Llaneza et al. 2012). In addition, we found limited differences between utilized range and potential expansion areas. Although we appreciate that this latter finding may partly have 
been a methodological artifact, we suggest that direct habitat suitability and ecological conditions may be less important for further wolf expansion. Instead, we suggest that local acceptance and policy decisions, for instance related to spatially structured harvest, may be the main drivers for the geographic distribution of a potential further wolf expansion in Sweden (Karlsson et al. 2004). From a management standpoint, this is an interesting situation where appropriate actions have a large scope of achieving defined management goals, although a situation where a wildlife species is mainly restricted by management policy also has its own unique challenges (Treves and Bruskotter 2011).

We appreciate several caveats to our study. The spatial resolution, environmental predictors and model settings can all influence MaxEnt model predictions, and the choice of the binary cut-off point of the model output can be very influential on the identification of suitable range areas. We conducted a rigorous model selection approach, and used one of the most objective measures of defining binary cut-off points available, although we appreciate that even this method may lack rigid theoretical support (Liu et al. 2013). While we regard our included variables to have captured most environmental variation, we did not include prey densities as a predictor since nationwide datasets are not available. One obvious problem with the Swedish wolf distribution is the strong latitudinal association to the reindeer husbandry area. This leads to strong confounding effects between the utilized training observations and any variables with a strong latitudinal gradient, for instance climate. Hence, and not surprisingly, our models were poor at predicting wolf expansion zones in northern Sweden. We regard this poor sensitivity to be a direct consequence of training our MaxEnt models on data that more or less were confined to central Sweden, and a broader distribution of wolf locations would likely have identified even further areas in the northern management region as suitable wolf range. Finally, our filtering of wolf observations, where we only included cells that had had observations in the previous year, or where any of the neighboring cells had had observations the previous year, in wolf range areas could either have been overly conservative or liberal. For instance, the lack of an observed nested expansion pattern suggested that the distribution range had changed geographically during the study period. Since our cell size of $72.25 \mathrm{~km}^{2}$ were substantially smaller than the mean home range size of Swedish wolves (Mattisson et al. 2013), these shifts could simply have been caused by annual movements within home ranges. However, species distribution models can be robust against shifts in resolution (Gusian et al. 2007), and we argue that the smallest ecologically sustainable home range size is an appropriate unit that could be directly utilized by management (Araújo et al. 2004).

To conclude, our overview of public data of the Swedish wolf population has shown a strong demographic expansion, but that a policy keeping the population out from the area utilized for reindeer husbandry have had strong impact on the development on wolf distribution range and on local wolf densities. Our maxent approach re-iterated these observations, and if including the reindeer husbandry area in our model we primarily identified areas in the central and southern parts of Sweden as potential expansion areas. Removing the reindeer husbandry area we instead identified substantial areas also in northern Sweden as potentially suitable for wolves. In addition, the extent of areas in northern Sweden were likely underestimated because of the strong correlation between latitude and the reindeer husbandry area. We suggest that further expansions of wolves in Sweden will be strongly defined by policy and public acceptance, and by political trade-offs between hosting wolves in densely populated areas in southern Sweden with associated high densities of cattle and sheep and social, cultural and economic costs of allowing wolves to expand into areas utilized for reindeer husbandry. We call for spatially explicit studies on the economic, social and cultural factors associated with large carnivore conflict and acceptance, as such 
information would be paramount for developing optimal management strategies in the spatial trade-offs that Sweden's wolf management authorities seem to face.

\section{Acknowledgements}

We are grateful to the Swedish Environmental Protection Agency, the Swedish Board of Agriculture and the National Veterinary Institute (SVA) for providing data for the study. Financial support was provided by The Spanish Ministry of Economy and Competitiveness (MINECO).

\section{References}

Ahmadi, M., Kaboli, M., Nourani, E., Shabani, A. A., Ashrafi, S. 2013. A predictive spatial model for gray wolf (Canis lupus) denning sites in a human-dominated landscape in western Iran. Ecological Research 28: 513-521.

Akaike, H. 1974. A new look at the statistical model identification. IEEE Transactions on Automatic Control 19: 716-723.

Araújo, M. B., Pearson, R. G., Thuillers, W., Erhard, M. 2005. Validation of species-climate impact models under climate change. Global Change Biology 11: 1-10.

Araújo, M. B., Thuiller, W., Williams, P. H., Reginster, I. 2004. Downscaling European species atlas distribution to a finer resolution: implications for conservation planning. Global Ecology and Biogeography 14: 17-30.

Baldwin, R. 2009. Use of maximum entropy modelling in wildlife research. Entropy 11: 854866.

Balme, G. A., Lindsey, P. A., Swanepoel, L. H., Hunter, L. T. B. 2013. Failure of research to address the rangewide conservation needs of large carnivores: leopard in South Africa as a case study. Conservation Letters 7: 3-11.

Bassi, E., Willis, S. G., Passilongo, D., Mattioli, L., Apollonio, M. 2015. Predicting the spatial distribution of wolf (Canis lupus) breeding areas in a mountainous region of central Italy. PLoS ONE 10: e0124698.

Borcard, D., Gillet, F., Legendre, P. 2011. Numerical ecology with R. New York: SpringerVerlag.

Boitani, L., et al. 2015. Key actions for Large Carnivore populations in Europe. Institute of Applied Ecology. Report to DG Environment, Contract no. 07.0307/2013/654446/SER/B3. Brussels: European Commission.

Burnham, K. P., Anderson, D. R. 2002. Model selection and multimodel inference. 2nd edn. New York: Springer-Verlag.

Chapron, G., et al. 2014. Recovery of large carnivores in Europe's modern human dominated landscapes. Science 346: 1517-1519.

Dalerum, F. 2014. What is the role of conservation biology for solving the environmental crisis? Ambio 43: 389-346.

Dalerum, F., Cameron, E. Z., Kunkel, K. E., Somers, M.J. 2009. Continental patterns of carnivore guild depletions: Implications for prioritizing global carnivore conservation. Biology Letters 5: 35-38.

Dalerum, F. Swanepoel, L. 2017. Humans as predators; an overview of predation strategies by hunters with contrasting motivational drivers. Arbor 193: a419

Daerga, L., Edin-Liljegren, A., Sjölander, P. 2008. Quality of life in relation to physical, psychosocial and socioeconomic conditions among reindeer-herding Sami. International Journal of Cirkumpolar Health 67: 10-28.

Davies-Mostert, H. T., Mills, M. G. M., Macdonald, D. W. 2009. A critical assessment of South Africa's managed metapopulation recovery strategy for African wild dogs, in: 
Hayward, M. W., Somers, M. J. (eds.), Reintroduction of top order predators, pp 10-42. Chichester: Whiley-Blackwell.

Dettki, H., Lofstrand, R., Edenius, L. 2003. Modeling habitat suitability for moose in coastal northern Sweden: Empirical vs process-oriented approaches. Ambio 8: 549-556.

Elith, J., Phillips, S. J., Hastie, T., Dudík, M., Chee, Y. E., Yates, C. J. 2011. A statistical explanation of MaxEnt for ecologists. Diversity and Distributions 17: 43-57.

Eriksson, M. 2016. Rurality and collective attitude effects on wolf policy. Sustainability 8: 711.

Eriksson, M., Sandström, C., Ericsson, G. 2015. Direct experience and attitude change towards bears and wolves. Wildlife Biology 21: 131-137.

Esenrink, M. and Vogel, G. 2006. The carnivore comeback. Science 314: 746-749.

Fielding, A. H., Bell, J. F. 1997. A review of methods for the assessment of prediction errors in conservation presence-absence models. EnvironmentalConservation 24: 38-49.

Flagstad, Ø., Walker, C. W., Vilà, C., Sundqvist, A. K., Fernholm, B., Hufthammer, A. K., Wiig, Ø., Koyola, I., Ellegren, H. 2003. Two centuries of the Scandinavian wolf population: patterns of genetic variability and migration during an era of dramatic decline. Molecular Ecology 12: 869-880.

Frank, J., Johansson, M., Flykt, A. 2015. Public attitude towards the implementation of management actions aimed at reducing human fear of brown bears and wolves. Wildlife Biology 21: 122-130.

Gusian, A., Graham, C. H., Elith, J., Huettmann, F., NCEAS Species Distribution Modelling Group 2007. Sensitivity of predictive species distribution models to change in grain size. Diversity and Distributions 13: 332-340.

Gränsdragningskommissionen för renskötselområdet 2006. Samernas sedvanemarker. SOU 2006:14. Stockholm: Swedish Ministry of Culture. [In Swedish]

Hanley, J.A., McNeil, B.J. 1982. The meaning and use of the area under a receiver operating characteristic (ROC) curve. Radiology 143: 29-36.

Hijmans, R. J., Phillips, S., Leathwick, J., Elith, J. 2017. Package "dismo". Available 201702-15: https://cran.r-project.org/web/packages/dismo/dismo.pdf

Jędrzejewski, W., Niedziałkowska, M., Nowak, S., Jędrzejewska, B. 2004. Habitat variables associated with wolf (Canis lupus) distribution and abundance in northern Poland. Diversity and Distributions 10: 225-233.

Kardos, M., Åkesson, M., Fountain , T., Flagstad, Ø., Liberg, O., Olason, P., Sand, H., Wabakken, P., Wikenros , C., Ellegren, H. 2018. Genomic consequences of intensive inbreeding in an isolated wolf population. Nature Ecology and Evolution 2: 124-131.

Karlsson, J., Andrén, H., Sand, H. 2004. Vad bestämmmer antalet vargar och vargens utbredning I framtiden?, in: Jansson, G., Seiler, C., Andrén, H. (eds.), Skogsvilt III: Vilt och landskap i förändring, pp. 54-57. Riddarhyttan: Swedish University of Agricultural Sciences. [In Swedish]

Karlsson, J., Brøseth, H., Sand, H., Andrén, H. 2007. Predicting occurrence of wolf territories in Scandinavia. Journal of Zoology 272: 276-283.

Karlsson, J., Sjöström, M. 2007. Human attitudes towards wolves, a matter of distance. Biological Conservation 137: 610-616.

Leader-Williams, N., Adams, W. M., Smith, R. J. (eds.). 2010. Trade-offs in conservation. Chichester: Wiley-Blackwell.

Liberg, O., Aronsson, Å., Sand, H., Wabakken, P., Maartmann, E., Svensson, L., Åkesson, M. 2012. Monitoring of wolves in Scandinavia. Hystrix, the Italian Journal of Mammalogy 23: 29-34. 
Liberg, O., Chapron, G., Wabakken, P., Pedersen, H. C., Hobbs, N. T., Sand, H. 2011. Shoot shovel and shut up: cryptic poaching slows restoration of a large carnivore in Europe. Proceedings of the Royal Society of London, Series B 279:910-915.

Liu, C., Newell, G., White, M. 2016. On the selection of thresholds for predicting species occurrence with presence-only data. Ecology and Evolution 6:337-347.

Liu, C., White, M., Newell, G. 2013. Selecting thresholds for the prediction of species occurrence with presence-only data. Journal of Biogeography 40: 778-789.

Llaneza, L., López-Bao, J.V., Sazatornil, V. 2012. Insights into wolf presence in humandominated landscapes: the relative role of food availability, humans and landscape attributes. Diversity and Distribution 18: 459-469.

Mace, G. 2014. Whose conservation? Science, 26: 1558-1560.

Madden, F. 2004. Creating coexistence between humans and wildlife: global perspectives on local efforts to address human-wildlife conflict. Human Dimensions of Wildlife. 9: 247257.

Mattisson, J., Sand, H., Wabakken, P., Gervasi, V., Liberg, O., Linnell, J. D.C., Rauset, G R., Pedersen, H. C. 2013. Home range size variation in a recovering wolf population: evaluating the effect of environmental, demographic, and social factors. Oecologia 173: 813-825.

Mech, L. D., Boitani, L. 2003. Wolves. Behaviour, Ecology and Conservation. Chicago: University of Chicago Press.

Merow, C, Smith, M. J., Silander Jr, J. A. 2013. A practical guide to MaxEnt for modeling species' distributions: what it does, and why inputs and settings matter. Ecography 36: 1058-1069.

Milleret, C. 2016. Spatial ecology of wolves in Scandinavia; From spatio-temporal dynamics of wolf pairs to wolf population dynamics. PhD Thesis, Hedmark University College. Evenstad, Norway.

Mladenoff, D. J., Sickley, T. A., Wydeven, A. P. 1999. Predicting grey wolf landscape colonization: logistic regression models vs. new field data. Ecological Applications 9: 37-44.

Moran, P. A. P. 1950. Notes on continuous stochastic phenomena. Biometrika 37: 17-23.

Muscarella, R., Galante, P. J., Soley-Guardia, M., Boria, R. A., Kass, J. M., Uriarte, M., Anderson, R. P. 2014. ENMeval: An R package for conducting spatially independent evaluations and estimating optimal model complexity for MAXENT ecological niche models. Methods in Ecology and Evolution 6: 1198-1205.

Naturvårdsverket 2016. Nationell förvaltningsplan för varg. Förvaltningsperioden 20142019. Stockholm: Swedish Environmental Protection Agency. [In Swedish]

Nyrén, U. 2012. Från utrotning till utbredning: Den svenska vargstammen som historiskt allmoge- och överhetsprojekt. Historisk Tidskrift 132: 365-391. [In Swedish]

Ordiz, A., Milleret, C., Kindberg, J., Månsson, J., Wabakken, P., Swenson, J. E., Sand, H. 2015. Wolves, people, and brown bears influence the expansion of the recolonizing wolf population in Scandinavia. Ecosphere 6: 284.

Peel, M. C., Finlayson, B. L., McAhon, T. A. 2007. Updated world map of the KöppenGeiger climate classification. Hydrology and Earth System Sciences 11: 1633-1644.

Penteriani, V., del Mar Delgado, M., Pinchera, F., Naves, J., Fernández-Gil, A., Kojola, I., Härkönen, S., Norberg, H., Frank, J., Fedriani, J. M., Sahlén, V., Støen, O. G., Swenson, J. E., Wabakken, P., Pellegrini, P., Herrero, S., López-Bao, J. V. 2016. Human behaviour can trigger large carnivore attacks in developed countries. Scientific Reports 6: 20552.

Phillips, S. J., Dudík, M. 2008. Modeling of species distributions with Maxent: new extensions and a comprehensive evaluation. Ecography 31: 161-175. 
Phillips, S. J., Anderson, R. P., Schapire, R. E. 2006. Maximum entropy modelling of species geographic distributions. Ecological Modelling 190: 231-259.

Phillips, S. J., Anderson, R. P., Dudík, M., Shapire, R. P., Blair, M. P. 2017. Opening the black box: an open-source release of Maxent. Ecography 40: 887-903.

Ripple, W. J., Beschta, R. L. 2011. Trophic cascades in Yellowstone: The first 15 years after wolf reintroduction. Biological Conservation 145: 205-2013.

Rodríguez-Gironés, M. A., Santamaría, L. 2006. A new algorithm to calculate the nestedness temperature of presence-absence matrices. Journal of Biogeography 33: 924-935.

Selby, L. 2016. Depredation of livestock and domestic dogs in Sweden by large carnivores: Are damages linked to carnivore density? Student thesis, University of Pretoria, Pretoria, South Africa.

Smith, J. B., Nielsen, C. K., Hellgren, E. C. 2015. Suitable habitat for recolonizing large carnivores in the midwestern USA. Oryx 50: 555-564.

Statistics Sweden. 2013. Land use in Sweden, sixth edition. Statistics Sweden, Örebro.

Swanepoel, L. H., Lindsey, P., Somers, M. J., van Hoven, W., Dalerum, F. 2013. Extent and fragmentation of suitable leopard habitat in South Africa. Animal Conservation 16: 4150 .

Swedish Government 2009. En ny rovdjursförvaltning. Government bill 2008/09: 210. Stockholm: Swedish Ministry of Agriculture [In Swedish]

Swedish Reindeer Husbandry Act. 1971. Rennäringslagen 1971:437. Stockholm: Swedish Ministry of Rural Affairs. [In Swedish]

Treves, A., Bruskotter, J. T. 2011. Gray wolf conservation at a crossroads. Bioscience 61: 584-585.

Treves, A., Karanth, K. U. 2003. Human-carnivore conflict and perspectives on carnivore management worldwide. Conservation Biology 17: 1491-1499.

Tufto, J., Andersen, R., Linnell, J. D. C. 1996. Habitat use and ecological correlates of home range size in a small cervid: The roe deer. Journal of Animal Ecology 65: 715-724.

Ulrich, W., Almeida-Neto, M., Gotelli, N. J. 2009. A consumer's guide to nestedness analysis. Oikos 118: 3-17.

Vilá, C.,Sundqvist, A. K., Flagstad, Ø., Seddon, J., Björnerfeldt, S., Kojola, I., Casulli, A., Sand, H., Wabakken, P., Ellegren, H. 2002. Rescue of a severely bottlenecked wolf (Canis lupus) population by a single immigrant. Proceedings of the Royal Society Series B Biology 270: 91-97.

Wabakken, P., Sand, H., Liberg, O., Bjärvall, A. 2001. The recovery, distribution, and population dynamics of wolves on the Scandinavian peninsula, 1978-1998. Canadian Journal of Zoology 79: 710-725.

Wabakken, P., Svensson, L., Maartmann, E., Åkesson, M, Flagstan, Ø. 2016. Bestandsåvervakning av ulv vinteren 2015/2016. Bestandsstatus for store rovdyr $i$ Skandinavia. 1-2016. [In Norwegian]

Warren, D. L., Seifert, S. 2011. Ecological niche modeling in Maxent: the importance of model complexity and the performance of model selection criteria. Ecological Applications 21: 335-342.

Wikenros, C., Sand, H., Wabakken, P., Liberg, O., Pedersen, H. C. 2009. Wolf predation on moose and roe deer: chase distances and outcome of encounters. Acta Theriologica 54: 207-218.

Woodroffe, R., Thirgood, S., Rabinowitz, A. 2005. People and wildlife: Conflict or coexistence? Cambridge: Cambridge University Press. 

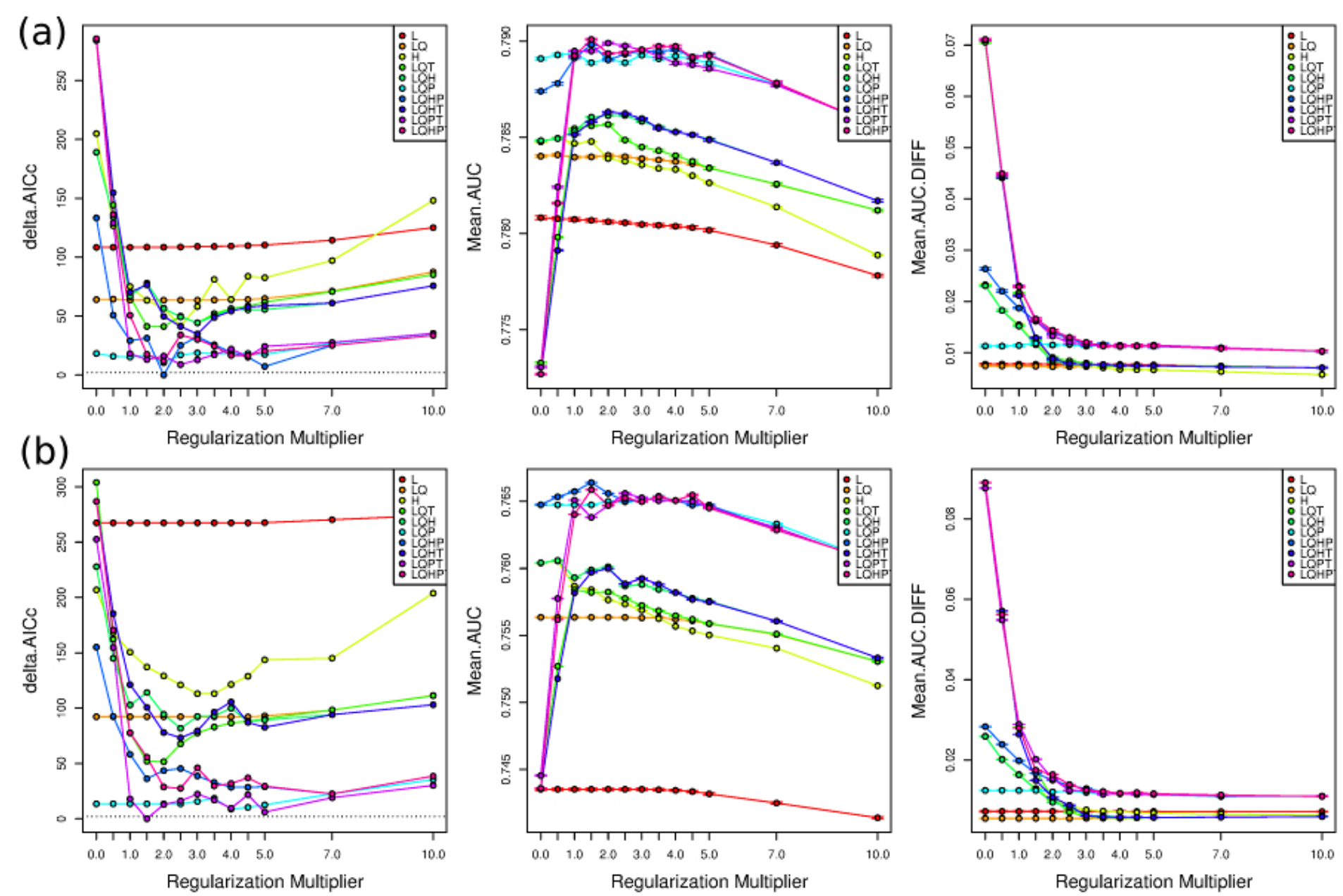

Regularization Multiplier

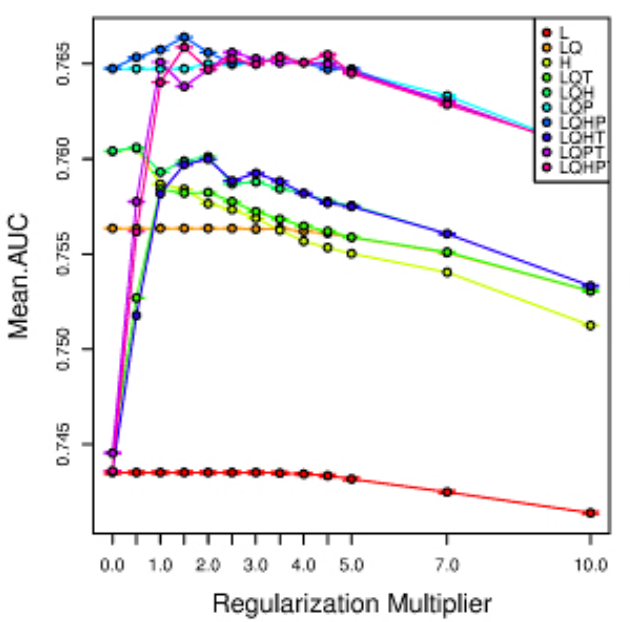

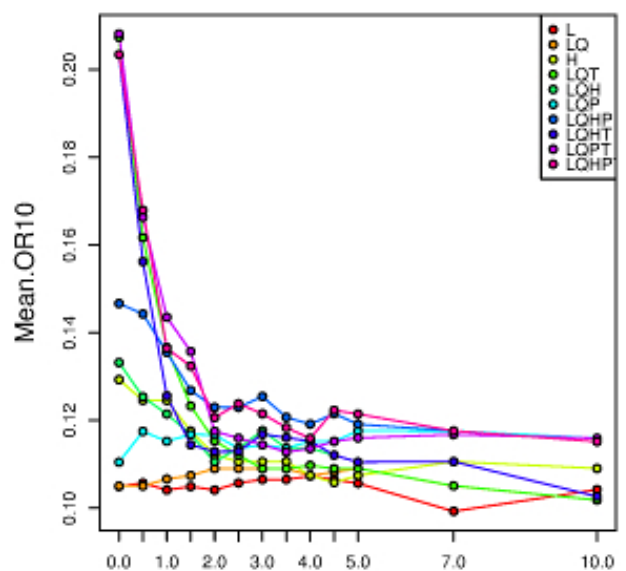

Regularization Multiplier

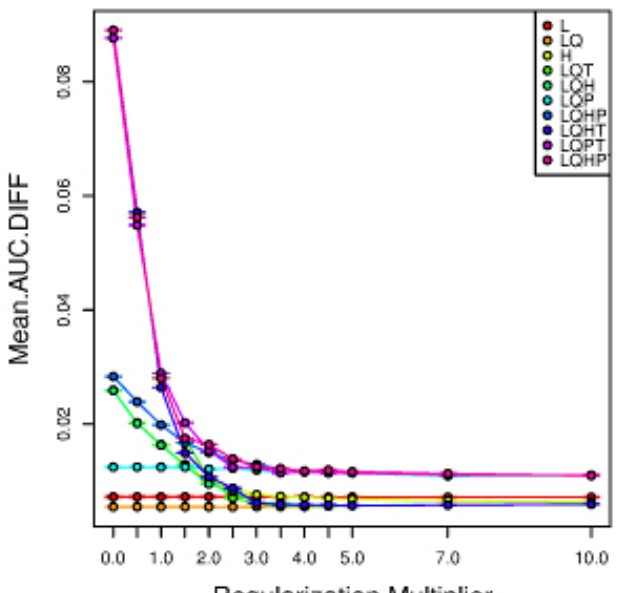

Regularization Multiplier

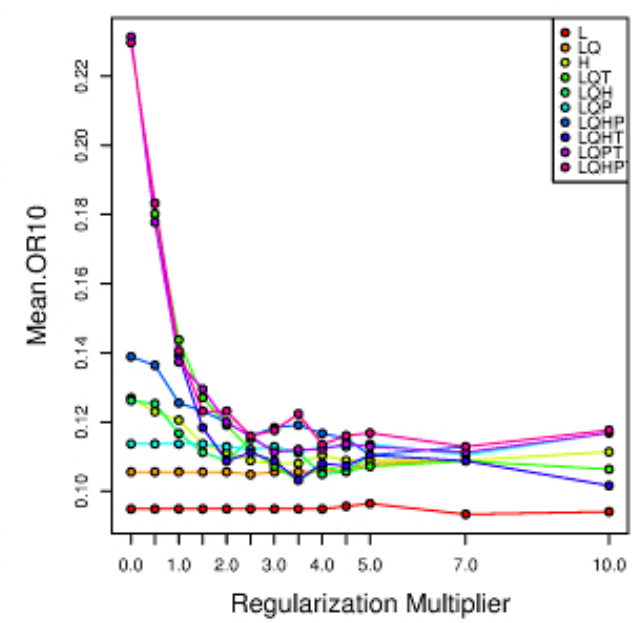

Fig. A1. Evaluation metrics for 130 different candidate models of wolf range suitability in Sweden using regularization multipliers from 0 to 10 and a set of 10 different feature type combinations ( $\mathrm{L}$ - linear, $\mathrm{Q}$ - quadratic, $\mathrm{H}$ - hinge, $\mathrm{P}$ - product, $\mathrm{T}$ - threshold) using a full set of 17 uncorrelated $\left(\mathrm{R}^{2}<\right.$ 0.7) predictors (a) and with the reindeer husbandry area excluded (b). 

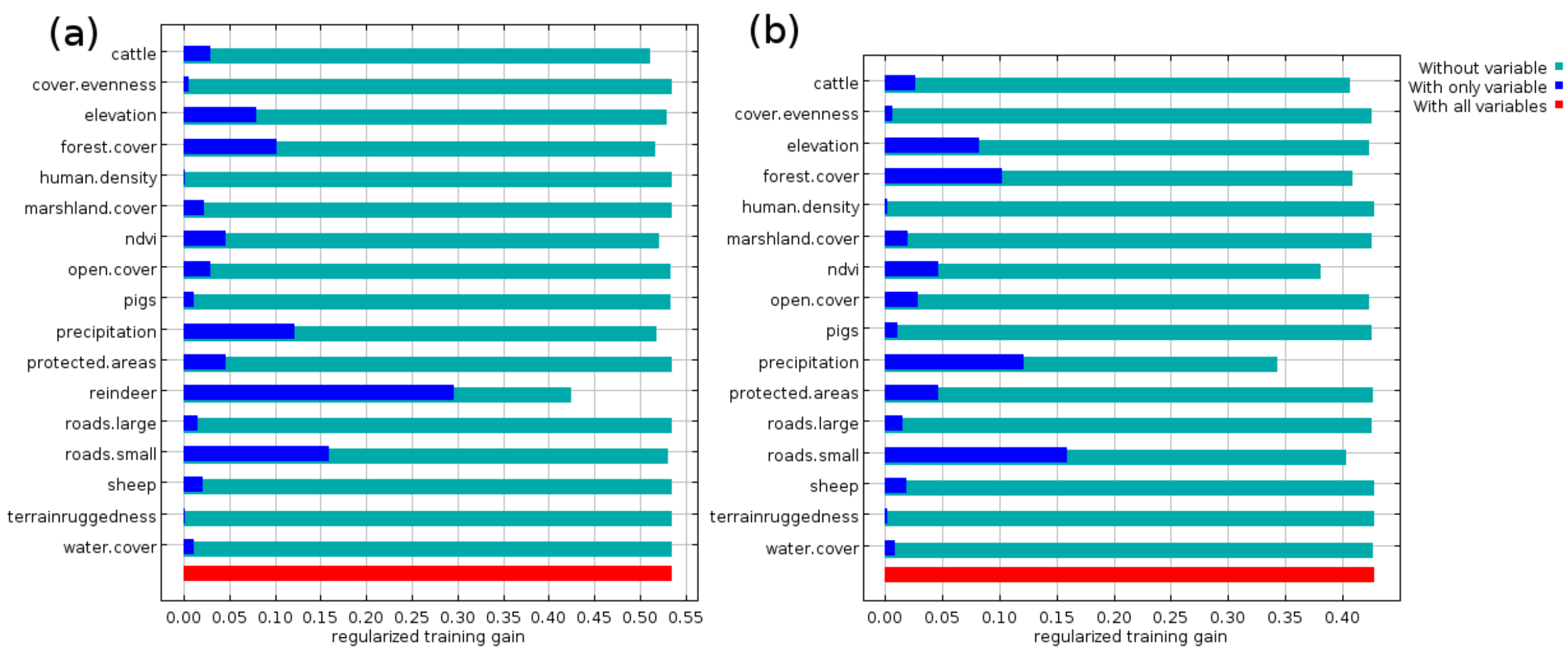

Fig. A2. Jacknife tests of variable contributions to two MaxEnt models of wolf range suitability in Sweden. The graphs show the gain in AUC when a variable is used on its own as well as the loss in AUC when it is removed from the full model. Results are shown for a model containing the full set of 17 environmental predictors (a) and a model not including the reindeer husbandry area (b). 
Table A1. Number of demographic units (family groups and scent marking pairs), geographic range, territory density and territory density within geographic range for Sweden, each management region and all counties during 2001 to 2015, except the island of Gotland.

\begin{tabular}{|c|c|c|c|c|c|}
\hline County/area & Year & $\begin{array}{l}\text { Demographic } \\
\text { units }\end{array}$ & $\begin{array}{l}\text { Geographic range } \\
(\mathrm{km} 2)\end{array}$ & $\begin{array}{l}\text { Demographic units per } \\
10000 \text { km2 }\end{array}$ & $\begin{array}{l}\text { Demographic units per } \\
10000 \mathrm{~km} 2 \text { within range }\end{array}$ \\
\hline \multirow[t]{15}{*}{ Sweden } & 2001 & 10.3 & 11777 & 0.24 & 8.75 \\
\hline & 2002 & 11.7 & 13800 & 0.27 & 8.48 \\
\hline & 2003 & 11.2 & 5274 & 0.26 & 21.24 \\
\hline & 2004 & 15.3 & 8887 & 0.35 & 17.22 \\
\hline & 2005 & 19.7 & 19797 & 0.45 & 9.95 \\
\hline & 2006 & 24.7 & 20158 & 0.57 & 12.25 \\
\hline & 2007 & 27 & 23337 & 0.62 & 11.57 \\
\hline & 2008 & 38.8 & 25432 & 0.89 & 15.26 \\
\hline & 2009 & 38.3 & 31790 & 0.88 & 12.05 \\
\hline & 2010 & 39.4 & 33669 & 0.91 & 11.70 \\
\hline & 2011 & 50.6 & 28322 & 1.16 & 17.87 \\
\hline & 2012 & 51.5 & 31212 & 1.18 & 16.50 \\
\hline & 2013 & 51.3 & 34825 & 1.18 & 14.73 \\
\hline & 2014 & 58 & 30056 & 1.33 & 19.30 \\
\hline & 2015 & 56.8 & 22903 & 1.31 & 24.80 \\
\hline \multirow{15}{*}{$\begin{array}{l}\text { Northern } \\
\text { management } \\
\text { region }\end{array}$} & 2001 & 0 & 0 & 0 & 0 \\
\hline & 2002 & 0 & 72.25 & 0 & 0 \\
\hline & 2003 & 0 & 650.25 & 0 & 0 \\
\hline & 2004 & 1 & 1011.5 & 0.04 & 9.90 \\
\hline & 2005 & 1 & 1734 & 0.02 & 2.90 \\
\hline & 2006 & 1 & 1589.5 & 0.02 & 3.10 \\
\hline & 2007 & 1 & 1589.5 & 0.02 & 3.10 \\
\hline & 2008 & 2 & 794.75 & 0.06 & 18.90 \\
\hline & 2009 & 1 & 1011.5 & 0.02 & 4.90 \\
\hline & 2010 & 2 & 2890 & 0.07 & 5.70 \\
\hline & 2011 & 3 & 2601 & 0.13 & 12.10 \\
\hline & 2012 & 2 & 2167.5 & 0.06 & 6.90 \\
\hline & 2013 & 4 & 3323.5 & 0.18 & 13.00 \\
\hline & 2014 & 3 & 2817.75 & 0.13 & 11.20 \\
\hline & 2015 & 1 & 1589.5 & 0.04 & 6.20 \\
\hline Norrbotten & 2001 & 0 & 0 & 0 & 0 \\
\hline \multirow[t]{14}{*}{$\mathrm{BD}$} & 2002 & 0 & 72.25 & 0 & 0 \\
\hline & 2003 & 0 & 216.75 & 0 & 0 \\
\hline & 2004 & 0 & 72.25 & 0 & 0 \\
\hline & 2005 & 0 & 72.25 & 0 & 0 \\
\hline & 2006 & 0 & 361.25 & 0 & 0 \\
\hline & 2007 & 0 & 505.75 & 0 & 0 \\
\hline & 2008 & 0 & 289 & 0 & 0 \\
\hline & 2009 & 0 & 361.25 & 0 & 0 \\
\hline & 2010 & 0 & 433.5 & 0 & 0 \\
\hline & 2011 & 0 & 0 & 0 & 0 \\
\hline & 2012 & 0 & 72.25 & 0 & 0 \\
\hline & 2013 & 0.33 & 216.75 & 0.03 & 15.20 \\
\hline & 2014 & 0 & 144.5 & 0 & 0 \\
\hline & 2015 & 0 & 0 & 0 & 0 \\
\hline Västerbotten & 2001 & 0 & 0 & 0 & 0 \\
\hline \multirow[t]{4}{*}{ AC } & 2002 & 0 & 0 & 0 & 0 \\
\hline & 2003 & 0 & 216.75 & 0 & 0 \\
\hline & 2004 & 0 & 216.75 & 0 & 0 \\
\hline & 2005 & 0 & 361.25 & 0 & 0 \\
\hline
\end{tabular}




\begin{tabular}{|c|c|c|c|c|c|}
\hline & 2006 & 0 & 72.25 & 0 & 0 \\
\hline & 2007 & 0 & 144.5 & 0 & 0 \\
\hline & 2008 & 0 & 72.25 & 0 & 0 \\
\hline & 2009 & 0 & 0 & 0 & 0 \\
\hline & 2010 & 0 & 144.5 & 0 & 0 \\
\hline & 2011 & 0 & 0 & 0 & 0 \\
\hline & 2012 & 0 & 0 & 0 & 0 \\
\hline & 2013 & 0.33 & 144.5 & 0.06 & 22.80 \\
\hline & 2014 & 0 & 0 & 0 & 0 \\
\hline & 2015 & 0 & 0 & 0 & 0 \\
\hline Västernorrland & 2001 & 0 & 0 & 0 & 0 \\
\hline Y & 2002 & 0 & 0 & 0 & 0 \\
\hline & 2003 & 0 & 72.25 & 0 & 0 \\
\hline & 2004 & 0 & 433.5 & 0 & 0 \\
\hline & 2005 & 0.5 & 1011.5 & & 4.90 \\
\hline & 2006 & 0.5 & 867 & & 5.80 \\
\hline & 2007 & 0.5 & 794.75 & & 6.30 \\
\hline & 2008 & 0.5 & 289 & & 17.30 \\
\hline & 2009 & 0 & 289 & 0 & 0.00 \\
\hline & 2010 & 0.33 & 289 & & 11.40 \\
\hline & 2011 & 0.83 & 505.75 & & 16.40 \\
\hline & 2012 & 0.5 & 361.25 & & 13.80 \\
\hline & 2013 & 0.33 & 1083.75 & 0.14 & 3.00 \\
\hline & 2014 & 1.33 & 1011.5 & & 13.10 \\
\hline & 2015 & 0.33 & 361.25 & & 9.10 \\
\hline Jämtland & 2001 & 0 & 0 & 0 & 0 \\
\hline Z & 2002 & 0 & 0 & 0 & 0 \\
\hline & 2003 & 0 & 144.5 & 0 & 0 \\
\hline & 2004 & 1 & 289 & 0.18 & 34.60 \\
\hline & 2005 & 0 & 289 & 0 & 0 \\
\hline & 2006 & 0 & 289 & 0 & 0 \\
\hline & 2007 & 0 & 144.5 & 0 & 0 \\
\hline & 2008 & 1 & 144.5 & 0.18 & 69.20 \\
\hline & 2009 & 0.5 & 361.25 & 0.09 & 13.80 \\
\hline & 2010 & 1.33 & 2023 & 0.24 & 6.60 \\
\hline & 2011 & 2.33 & 2095.25 & 0.43 & 11.10 \\
\hline & 2012 & 1 & 1734 & 0.18 & 5.80 \\
\hline & 2013 & 3.33 & 1878.5 & 0.61 & 17.70 \\
\hline & 2014 & 1.83 & 1661.75 & 0.34 & 11.00 \\
\hline & 2015 & 0.66 & 1228.25 & 0.12 & 5.40 \\
\hline Central & 2001 & 10 & 11632.25 & 0.83 & 8.90 \\
\hline management & 2002 & 12 & 13510.75 & 0.94 & 8.70 \\
\hline region & 2003 & 11 & 4624 & 0.89 & 24.10 \\
\hline & 2004 & 14 & 7803 & 1.15 & 18.40 \\
\hline & 2005 & 19 & 17990.25 & 1.54 & 10.70 \\
\hline & 2006 & 24 & 18423.75 & 1.94 & 13.10 \\
\hline & 2007 & 26 & 21602.75 & 2.12 & 12.30 \\
\hline & 2008 & 37 & 24420.5 & 2.99 & 15.30 \\
\hline & 2009 & 38 & 30128.25 & 3.03 & 12.50 \\
\hline & 2010 & 38 & 30634 & 3.03 & 12.30 \\
\hline & 2011 & 47 & 25504.25 & 3.80 & 18.60 \\
\hline & 2012 & 50 & 28827.75 & 4.01 & 17.30 \\
\hline & 2013 & 47 & 30923 & 3.77 & 15.20 \\
\hline & 2014 & 55 & 26515.75 & 4.39 & 20.70 \\
\hline & 2015 & 56 & 21097 & 4.47 & 26.50 \\
\hline Gävleborg & 2001 & 1 & 505.75 & 0.51 & 19.80 \\
\hline
\end{tabular}




\begin{tabular}{|c|c|c|c|c|c|}
\hline \multirow[t]{14}{*}{$\mathrm{X}$} & 2002 & 1.5 & 939.25 & 0.77 & 16.00 \\
\hline & 2003 & 1 & 216.75 & 0.51 & 46.10 \\
\hline & 2004 & 1.5 & 939.25 & 0.77 & 16.00 \\
\hline & 2005 & 3.5 & 2384.25 & 1.79 & 14.70 \\
\hline & 2006 & 3.5 & 2456.5 & 1.79 & 14.20 \\
\hline & 2007 & 4.5 & 4335 & 2.31 & 10.40 \\
\hline & 2008 & 6 & 5057.5 & 3.08 & 11.90 \\
\hline & 2009 & 4 & 5057.5 & 2.05 & 7.90 \\
\hline & 2010 & 4.83 & 4335 & 2.48 & 11.10 \\
\hline & 2011 & 5.3 & 3251.25 & 2.72 & 16.30 \\
\hline & 2012 & 3 & 3179 & 1.54 & 9.40 \\
\hline & 2013 & 2.83 & 2601 & 1.45 & 10.90 \\
\hline & 2014 & 4.33 & 2890 & 2.22 & 15.00 \\
\hline & 2015 & 5.16 & 2601 & 2.65 & 19.80 \\
\hline Dalarna & 2001 & 3 & 3684.75 & 1.00 & 8.10 \\
\hline \multirow[t]{14}{*}{ W } & 2002 & 2.83 & 4118.25 & 0.94 & 6.90 \\
\hline & 2003 & 1.83 & 578 & 0.61 & 31.70 \\
\hline & 2004 & 2.5 & 1589.5 & 0.83 & 15.70 \\
\hline & 2005 & 4.5 & 5924.5 & 1.50 & 7.60 \\
\hline & 2006 & 8 & 6358 & 2.66 & 12.60 \\
\hline & 2007 & 8.33 & 6285.75 & 2.77 & 13.30 \\
\hline & 2008 & 12.16 & 8236.5 & 4.05 & 14.80 \\
\hline & 2009 & 11.16 & 10187.25 & 3.71 & 11.00 \\
\hline & 2010 & 13.16 & 9464.75 & 4.38 & 13.90 \\
\hline & 2011 & 15.83 & 9392.5 & 5.27 & 16.90 \\
\hline & 2012 & 20.33 & 9898.25 & 6.76 & 20.50 \\
\hline & 2013 & 13.5 & 8670 & 4.49 & 15.60 \\
\hline & 2014 & 14.83 & 8164.25 & 4.93 & 18.20 \\
\hline & 2015 & 14.16 & 5996.75 & 4.71 & 23.60 \\
\hline Stockholm & 2001 & 0 & 0 & 0 & 0 \\
\hline \multirow[t]{14}{*}{$\mathrm{AB}$} & 2002 & 0 & 144.5 & 0 & 0 \\
\hline & 2003 & 0 & 0 & 0 & 0 \\
\hline & 2004 & 0 & 0 & 0 & 0 \\
\hline & 2005 & 0 & 144.5 & 0 & 0 \\
\hline & 2006 & 0 & 72.25 & 0 & 0 \\
\hline & 2007 & 0 & 0 & 0 & 0 \\
\hline & 2008 & 0 & 0 & 0 & 0 \\
\hline & 2009 & 0 & 72.25 & 0 & 0 \\
\hline & 2010 & 1 & 144.5 & 1.57 & 69.20 \\
\hline & 2011 & 1 & 289 & 1.57 & 34.60 \\
\hline & 2012 & 1 & 289 & 1.57 & 34.60 \\
\hline & 2013 & 1 & 578 & 1.57 & 17.30 \\
\hline & 2014 & 0 & 0 & 0 & 0 \\
\hline & 2015 & 1 & 144.5 & 1.57 & 69.20 \\
\hline Uppsala & 2001 & 0 & 144.5 & 0 & 0 \\
\hline \multirow[t]{11}{*}{$\mathrm{C}$} & 2002 & 0 & 433.5 & 0 & 0 \\
\hline & 2003 & 0 & 72.25 & 0 & 0 \\
\hline & 2004 & 0 & 0 & 0 & 0 \\
\hline & 2005 & 0 & 0 & 0 & 0 \\
\hline & 2006 & 0 & 72.25 & 0 & 0 \\
\hline & 2007 & 0 & 216.75 & 0 & 0 \\
\hline & 2008 & 0 & 0 & 0 & 0 \\
\hline & 2009 & 0 & 0 & 0 & 0 \\
\hline & 2010 & 0 & 0 & 0 & 0 \\
\hline & 2011 & 0 & 0 & 0 & 0 \\
\hline & 2012 & 0 & 0 & 0 & 0 \\
\hline
\end{tabular}




\begin{tabular}{|c|c|c|c|c|c|}
\hline & 2013 & 0 & 216.75 & 0 & 0 \\
\hline & 2014 & 0 & 144.5 & 0 & 0 \\
\hline & 2015 & 0.5 & 216.75 & 0.58 & 23.10 \\
\hline Västmanland & 2001 & 0 & 216.75 & 0 & 0 \\
\hline $\mathrm{U}$ & 2002 & 0 & 289 & 0 & 0 \\
\hline & 2003 & 0 & 144.5 & 0 & 0 \\
\hline & 2004 & 0.5 & 361.25 & 0.84 & 13.80 \\
\hline & 2005 & 0.5 & 216.75 & 0.84 & 23.10 \\
\hline & 2006 & 0.5 & 144.5 & 0.84 & 34.60 \\
\hline & 2007 & 0.5 & 289 & 0.84 & 17.30 \\
\hline & 2008 & 0.83 & 433.5 & 1.40 & 19.10 \\
\hline & 2009 & 0.83 & 1083.75 & 1.40 & 7.70 \\
\hline & 2010 & 1.8 & 1300.5 & 3.04 & 13.80 \\
\hline & 2011 & 3.33 & 1661.75 & 5.62 & 20.00 \\
\hline & 2012 & 4 & 1806.25 & 6.75 & 22.10 \\
\hline & 2013 & 3 & 1011.5 & 5.06 & 29.70 \\
\hline & 2014 & 3.33 & 1228.25 & 5.62 & 27.10 \\
\hline & 2015 & 5 & 1445 & 8.44 & 34.60 \\
\hline Örebro & 2001 & 1 & 1950.75 & 1.04 & 5.10 \\
\hline $\mathrm{T}$ & 2002 & 0.83 & 1661.75 & 0.86 & 5.00 \\
\hline & 2003 & 2.16 & 794.75 & 2.25 & 27.20 \\
\hline & 2004 & 3 & 1661.75 & 3.12 & 18.10 \\
\hline & 2005 & 2.5 & 2312 & 2.60 & 10.80 \\
\hline & 2006 & 2 & 2312 & 2.08 & 8.70 \\
\hline & 2007 & 3.83 & 2962.25 & 3.99 & 12.90 \\
\hline & 2008 & 2.99 & 2673.25 & 3.11 & 11.20 \\
\hline & 2009 & 2.66 & 2962.25 & 2.77 & 9.00 \\
\hline & 2010 & 1.66 & 3612.5 & 1.73 & 4.60 \\
\hline & 2011 & 4.33 & 3251.25 & 4.51 & 13.30 \\
\hline & 2012 & 6.33 & 4407.25 & 6.59 & 14.40 \\
\hline & 2013 & 6.83 & 4768.5 & 7.11 & 14.30 \\
\hline & 2014 & 8.83 & 4046 & 9.19 & 21.80 \\
\hline & 2015 & 8.33 & 2384.25 & 8.67 & 34.90 \\
\hline Värmland & 2001 & 4.33 & 3757 & 2.25 & 11.50 \\
\hline S & 2002 & 5.58 & 4985.25 & 2.90 & 11.20 \\
\hline & 2003 & 4.16 & 2601 & 2.16 & 16.00 \\
\hline & 2004 & 5.33 & 2384.25 & 2.77 & 22.40 \\
\hline & 2005 & 6.66 & 5491 & 3.47 & 12.10 \\
\hline & 2006 & 7.16 & 5491 & 3.73 & 13.00 \\
\hline & 2007 & 7.33 & 5780 & 3.81 & 12.70 \\
\hline & 2008 & 9.66 & 5346.5 & 5.03 & 18.10 \\
\hline & 2009 & 13.83 & 6647 & 7.20 & 20.80 \\
\hline & 2010 & 12.33 & 8092 & 6.42 & 15.20 \\
\hline & 2011 & 14.83 & 5202 & 7.72 & 28.50 \\
\hline & 2012 & 14.33 & 6791.5 & 7.46 & 21.10 \\
\hline & 2013 & 18 & 8597.75 & 9.37 & 20.90 \\
\hline & 2014 & 20.5 & 8092 & 10.67 & 25.30 \\
\hline & 2015 & 19.66 & 6574.75 & 10.23 & 29.90 \\
\hline V. Götaland & 2001 & 1 & 1372.75 & 0.39 & 7.30 \\
\hline $\mathrm{O}$ & 2002 & 1 & 939.25 & 0.39 & 10.60 \\
\hline & 2003 & 2 & 216.75 & 0.78 & 92.30 \\
\hline & 2004 & 1.5 & 867 & 0.59 & 17.30 \\
\hline & 2005 & 1.5 & 1517.25 & 0.59 & 9.90 \\
\hline & 2006 & 3 & 1517.25 & 1.18 & 19.80 \\
\hline & 2007 & 2 & 1734 & 0.78 & 11.50 \\
\hline & 2008 & 5.66 & 2673.25 & 2.22 & 21.20 \\
\hline
\end{tabular}




\begin{tabular}{|c|c|c|c|c|c|}
\hline & 2009 & 5.33 & 4118.25 & 2.09 & 12.90 \\
\hline & 2010 & 3 & 3684.75 & 1.18 & 8.10 \\
\hline & 2011 & 2.8 & 2456.5 & 1.10 & 11.40 \\
\hline & 2012 & 1 & 2456.5 & 0.39 & 4.10 \\
\hline & 2013 & 1.83 & 4479.5 & 0.72 & 4.10 \\
\hline & 2014 & 3 & 1950.75 & 1.18 & 15.40 \\
\hline & 2015 & 2 & 1734 & 0.78 & 11.50 \\
\hline Southern & 2001 & 0 & 144.5 & & 0 \\
\hline management & 2002 & 0 & 216.75 & 0 & 0 \\
\hline region & 2003 & 0 & 0 & 0 & 0 \\
\hline & 2004 & 0 & 72.25 & 0 & 0 \\
\hline & 2005 & 0 & 72.25 & 0 & 0 \\
\hline & 2006 & 0 & 144.5 & 0 & 0 \\
\hline & 2007 & 0 & 144.5 & 0 & 0 \\
\hline & 2008 & 0 & 216.75 & 0 & 0 \\
\hline & 2009 & 0 & 650.25 & 0 & 0 \\
\hline & 2010 & 0 & 144.5 & 0 & 0 \\
\hline & 2011 & 0 & 216.75 & 0 & 0 \\
\hline & 2012 & 0 & 216.75 & 0 & 0 \\
\hline & 2013 & 0 & 578 & 0 & 0 \\
\hline & 2014 & 0 & 722.5 & 0 & 0 \\
\hline & 2015 & 0 & 216.75 & 0 & 0 \\
\hline Södermanland & 2001 & 0 & 0 & 0 & 0 \\
\hline $\mathrm{D}$ & 2002 & 0 & 0 & 0 & 0 \\
\hline & 2003 & 0 & 0 & 0 & 0 \\
\hline & 2004 & 0 & 0 & 0 & 0 \\
\hline & 2005 & 0 & 0 & 0 & 0 \\
\hline & 2006 & 0 & 0 & 0 & 0 \\
\hline & 2007 & 0 & 0 & 0 & 0 \\
\hline & 2008 & 0 & 72.25 & 0 & 0 \\
\hline & 2009 & 0 & 433.5 & 0 & 0 \\
\hline & 2010 & 0 & 0 & 0 & 0 \\
\hline & 2011 & 0 & 0 & 0 & 0 \\
\hline & 2012 & 0 & 0 & 0 & 0 \\
\hline & 2013 & 0 & 0 & 0 & 0 \\
\hline & 2014 & 0 & 0 & 0 & 0 \\
\hline & 2015 & 0 & 72.25 & 0 & 0 \\
\hline Östergötland & 2001 & 0 & 0 & 0 & 0 \\
\hline $\mathrm{E}$ & 2002 & 0 & 216.75 & 0 & 0 \\
\hline & 2003 & 0 & 0 & 0 & 0 \\
\hline & 2004 & 0 & 0 & 0 & 0 \\
\hline & 2005 & 0 & 0 & 0 & 0 \\
\hline & 2006 & 0 & 0 & 0 & 0 \\
\hline & 2007 & 0 & 72.25 & 0 & 0 \\
\hline & 2008 & 0 & 72.25 & 0 & 0 \\
\hline & 2009 & 0 & 0 & 0 & 0 \\
\hline & 2010 & 0 & 144.5 & 0 & 0 \\
\hline & 2011 & 0 & 144.5 & 0 & 0 \\
\hline & 2012 & 0 & 0 & 0 & 0 \\
\hline & 2013 & 0 & 0 & 0 & 0 \\
\hline & 2014 & 0 & 0 & 0 & 0 \\
\hline & 2015 & 0 & 0 & 0 & 0 \\
\hline Kalmar & 2001 & 0 & 72.25 & 0 & 0 \\
\hline $\mathrm{H}$ & 2002 & 0 & 0 & 0 & 0 \\
\hline & 2003 & 0 & 0 & 0 & 0 \\
\hline & 2004 & 0 & 0 & 0 & 0 \\
\hline
\end{tabular}




\begin{tabular}{|c|c|c|c|c|c|}
\hline & 2005 & 0 & 72.25 & 0 & 0 \\
\hline & 2006 & 0 & 0 & 0 & 0 \\
\hline & 2007 & 0 & 0 & 0 & 0 \\
\hline & 2008 & 0 & 0 & 0 & 0 \\
\hline & 2009 & 0 & 0 & 0 & 0 \\
\hline & 2010 & 0 & 0 & 0 & 0 \\
\hline & 2011 & 0 & 0 & 0 & 0 \\
\hline & 2012 & 0 & 72.25 & 0 & 0 \\
\hline & 2013 & 0 & 72.25 & 0 & 0 \\
\hline & 2014 & 0 & 0 & 0 & 0 \\
\hline & 2015 & 0 & 0 & 0 & 0 \\
\hline \multirow{15}{*}{$\begin{array}{l}\text { Jonkoping } \\
\mathrm{F}\end{array}$} & 2001 & 0 & 0 & 0 & 0 \\
\hline & 2002 & 0 & 0 & 0 & 0 \\
\hline & 2003 & 0 & 0 & 0 & 0 \\
\hline & 2004 & 0 & 72.25 & 0 & 0 \\
\hline & 2005 & 0 & 0 & 0 & 0 \\
\hline & 2006 & 0 & 0 & 0 & 0 \\
\hline & 2007 & 0 & 0 & 0 & 0 \\
\hline & 2008 & 0 & 0 & 0 & 0 \\
\hline & 2009 & 0 & 0 & 0 & 0 \\
\hline & 2010 & 0 & 0 & 0 & 0 \\
\hline & 2011 & 0 & 0 & 0 & 0 \\
\hline & 2012 & 0 & 0 & 0 & 0 \\
\hline & 2013 & 0 & 144.5 & 0 & 0 \\
\hline & 2014 & 0 & 144.5 & 0 & 0 \\
\hline & 2015 & 0 & 144.5 & 0 & 0 \\
\hline Blekinge & 2001 & 0 & 0 & 0 & $\overline{0}$ \\
\hline \multirow{14}{*}{$\begin{array}{l}\text { Dlekilge } \\
\text { K }\end{array}$} & 2002 & 0 & 0 & 0 & 0 \\
\hline & 2003 & 0 & 0 & 0 & 0 \\
\hline & 2004 & 0 & 0 & 0 & 0 \\
\hline & 2005 & 0 & 0 & 0 & 0 \\
\hline & 2006 & 0 & 0 & 0 & 0 \\
\hline & 2007 & 0 & 0 & 0 & 0 \\
\hline & 2008 & 0 & 0 & 0 & 0 \\
\hline & 2009 & 0 & 0 & 0 & 0 \\
\hline & 2010 & 0 & 0 & 0 & 0 \\
\hline & 2011 & 0 & 0 & 0 & 0 \\
\hline & 2012 & 0 & 0 & 0 & 0 \\
\hline & 2013 & 0 & 0 & 0 & 0 \\
\hline & 2014 & 0 & 0 & 0 & 0 \\
\hline & 2015 & 0 & 0 & 0 & 0 \\
\hline Kronoberg & 2001 & 0 & 72.25 & 0 & $\overline{0}$ \\
\hline \multirow[t]{14}{*}{ G } & 2002 & 0 & 0 & 0 & 0 \\
\hline & 2003 & 0 & 0 & 0 & 0 \\
\hline & 2004 & 0 & 0 & 0 & 0 \\
\hline & 2005 & 0 & 0 & 0 & 0 \\
\hline & 2006 & 0 & 0 & 0 & 0 \\
\hline & 2007 & 0 & 0 & 0 & 0 \\
\hline & 2008 & 0 & 0 & 0 & 0 \\
\hline & 2009 & 0 & 0 & 0 & 0 \\
\hline & 2010 & 0 & 0 & 0 & 0 \\
\hline & 2011 & 0 & 72.25 & 0 & 0 \\
\hline & 2012 & 0 & 72.25 & 0 & 0 \\
\hline & 2013 & 0 & 289 & 0 & 0 \\
\hline & 2014 & 0 & 289 & 0 & 0 \\
\hline & 2015 & 0 & 0 & 0 & 0 \\
\hline
\end{tabular}




\begin{tabular}{|c|c|c|c|c|c|}
\hline Halland & 2001 & 0 & 0 & 0 & 0 \\
\hline \multirow[t]{14}{*}{$\mathrm{N}$} & 2002 & 0 & 0 & 0 & 0 \\
\hline & 2003 & 0 & 0 & 0 & 0 \\
\hline & 2004 & 0 & 0 & 0 & 0 \\
\hline & 2005 & 0 & 0 & 0 & 0 \\
\hline & 2006 & 0 & 144.5 & 0 & 0 \\
\hline & 2007 & 0 & 72.25 & 0 & 0 \\
\hline & 2008 & 0 & 72.25 & 0 & 0 \\
\hline & 2009 & 0 & 216.75 & 0 & 0 \\
\hline & 2010 & 0 & 0 & 0 & 0 \\
\hline & 2011 & 0 & 0 & 0 & 0 \\
\hline & 2012 & 0 & 72.25 & 0 & 0 \\
\hline & 2013 & 0 & 72.25 & 0 & 0 \\
\hline & 2014 & 0 & 0 & 0 & 0 \\
\hline & 2015 & 0 & 0 & 0 & 0 \\
\hline Skåne & 2001 & 0 & 0 & 0 & 0 \\
\hline \multirow{14}{*}{$\mathrm{M}$} & 2002 & 0 & 0 & 0 & 0 \\
\hline & 2003 & 0 & 0 & 0 & 0 \\
\hline & 2004 & 0 & 0 & 0 & 0 \\
\hline & 2005 & 0 & 0 & 0 & 0 \\
\hline & 2006 & 0 & 0 & 0 & 0 \\
\hline & 2007 & 0 & 0 & 0 & 0 \\
\hline & 2008 & 0 & 0 & 0 & 0 \\
\hline & 2009 & 0 & 0 & 0 & 0 \\
\hline & 2010 & 0 & 0 & 0 & 0 \\
\hline & 2011 & 0 & 0 & 0 & 0 \\
\hline & 2012 & 0 & 0 & 0 & 0 \\
\hline & 2013 & 0 & 0 & 0 & 0 \\
\hline & 2014 & 0 & 289 & 0 & 0 \\
\hline & 2015 & 0 & 0 & 0 & 0 \\
\hline
\end{tabular}


Table A2. Evaluation metrics for the ten models with the lowest AICc values.

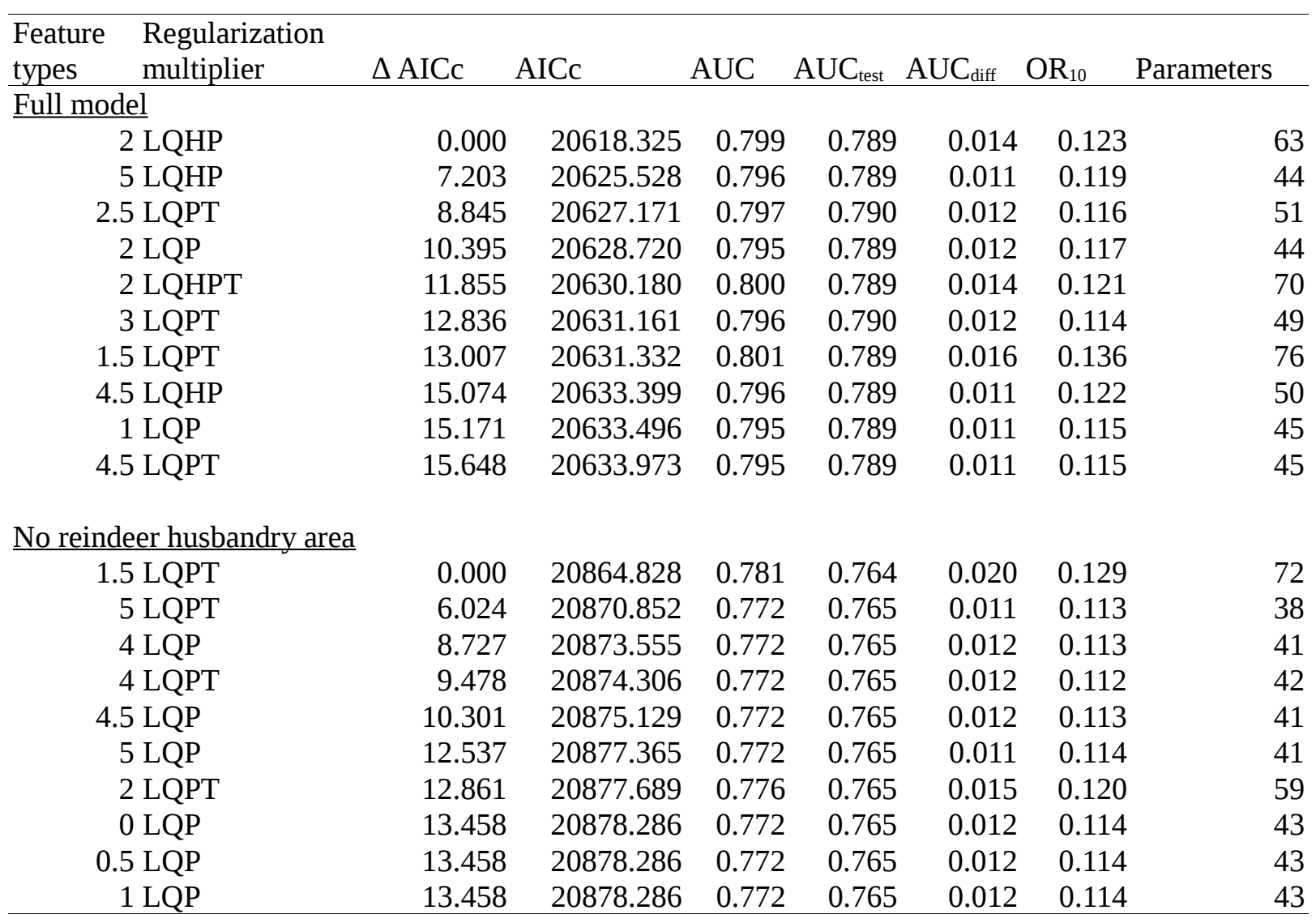


Table A3. Variable contributions to two MaxEnt models predicitng wolf distribution range in Sweden, one containing a full set of 17 uncorrelated $\left(\mathrm{R}^{2}>0.7\right)$ variables (Model I) and one model that did not include the reindeer husbandry area (Model II). Variable contributions were estimated heuristically as percent contribution to training gain during each iteration in the model fitting process.

\begin{tabular}{lrr}
\hline Variable & Model I & Model II \\
\hline Reindeer husbandry area & 56.1 & \\
Forest cover & 14.9 & 17.1 \\
Precipitation & 9.7 & 29.3 \\
Cattle density & 9.5 & 6.1 \\
NDVI & 3.3 & 13.7 \\
Small roads (<7 m. width) & 3.1 & 30.4 \\
Elevation & 2.3 & 1.3 \\
Sheep density & 0.3 & 0 \\
Marshland cover & 0.3 & 0.1 \\
Protected areas & 0.2 & 0.3 \\
Open cover & 0.1 & 0.3 \\
Cover evenness & 0.1 & 0.3 \\
Human density & 0.1 & 0 \\
Pig density & 0.1 & 0.5 \\
Water cover & 0 & 0.3 \\
Large roads (>7 m. width) & 0 & 0.2 \\
Terrain ruggedness & 0 & 0 \\
\hline
\end{tabular}

